\title{
Impact of land-water sensitivity contrast on MOPITT retrievals and trends over a coastal city
}

\author{
Ian Ashpole ${ }^{1}$ and Aldona Wiacek ${ }^{1,2}$ \\ ${ }^{1}$ Department of Environmental Science, Saint Mary's University, Halifax, Canada \\ ${ }^{2}$ Department of Astronomy and Physics, Saint Mary's University, Halifax, Canada
}

Correspondence: Ian Ashpole (ian.ashpole@smu.ca)

Received: 11 November 2019 - Discussion started: 18 December 2019

Revised: 24 April 2020 - Accepted: 13 May 2020 - Published: 2 July 2020

\begin{abstract}
We compare MOPITT Version 7 (V7) Level 2 (L2) and Level 3 (L3) carbon monoxide (CO) products for the $1^{\circ} \times 1^{\circ} \mathrm{L} 3$ grid box containing the coastal city of Halifax, Canada (longitude $-63.58^{\circ}$, latitude $44.65^{\circ}$ ), with a focus on the seasons DJF and JJA, and highlight a limitation in the L3 products that has significant consequences for the temporal trends in near-surface $\mathrm{CO}$ identified using those data. Because this grid box straddles the coastline, the MOPITT L3 products are created from the finer spatial resolution L2 products that are retrieved over both land and water, with a greater contribution from retrievals over water because more of the grid box lies over water than land. We create alternative $\mathrm{L} 3$ products for this grid box by separately averaging the bounded L2 retrievals over land (L3L) and water (L3W) and demonstrate that profile and total column CO (TCO) concentrations, retrieved at the same time, differ depending on whether the retrieval took place over land or water. These differences $(\triangle \mathrm{RET})$ are greatest in the lower troposphere (LT), where mean retrieved volume mixing ratios (VMRs) are greater in $\mathrm{L} 3 \mathrm{~W}$ than $\mathrm{L} 3 \mathrm{~L}$, with maximum mean differences of $11.6 \%$ (14.3 ppbv, $p=0.001)$ at the surface level in JJA. Retrieved CO concentrations are more similar, on average, in the middle and upper troposphere (MT and UT), although large differences (in excess of $40 \%$ ) do infrequently occur. TCO is also greater in $\mathrm{L} 3 \mathrm{~W}$ than $\mathrm{L} 3 \mathrm{~L}$ in both seasons. By analysing $\mathrm{L} 3 \mathrm{~L}$ and $\mathrm{L} 3 \mathrm{~W}$ retrieval averaging kernels and simulations of these retrievals, we demonstrate that, in JJA, $\triangle \mathrm{RET}$ is strongly influenced by differences in retrieval sensitivity over land and water, especially close to the surface where L3L has significantly greater information content than L3W. In DJF, land-water differences in retrieval sensitivity are much less pronounced and appear to have less of an im-
\end{abstract}

pact on $\triangle$ RET, which analysis of wind directions suggests is more likely to reflect differences in true profile concentrations (i.e. real differences). The original L3 time series for the $1^{\circ} \times 1^{\circ}$ grid box containing Halifax (L3O) corresponds much more closely to $\mathrm{L} 3 \mathrm{~W}$ than $\mathrm{L} 3 \mathrm{~L}$, owing to the greater contribution from L2 retrievals over water than land. Thus, in JJA, variability in retrieved $\mathrm{CO}$ concentrations close to the surface in $\mathrm{L} 3 \mathrm{O}$ is suppressed compared to $\mathrm{L} 3 \mathrm{~L}$, and a declining trend detected using weighted least squares (WLS) regression analysis is significantly slower in $\mathrm{L} 3 \mathrm{O}$ (strongest surface level trend identifiable is $\left.-1.35( \pm 0.35) \mathrm{ppbv} \mathrm{yr}^{-1}\right)$ than L3L $\left(-2.85( \pm 0.60) \mathrm{ppbv} \mathrm{yr}^{-1}\right)$. This is because contributing L2 retrievals over water are closely tied to a priori $\mathrm{CO}$ concentrations used in the retrieval, owing to their lack of near-surface sensitivity in JJA, and these are based on monthly climatological $\mathrm{CO}$ profiles from a chemical transport model and therefore have no yearly change (surface level trend in L3W

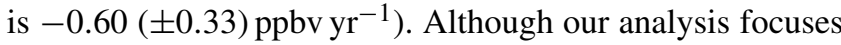
on DJF and JJA, we demonstrate that the findings also apply to MAM and SON. The results that we report here suggest that similar analyses be performed for other coastal cities before using MOPITT surface CO.

\section{Introduction}

The Measurement of Pollution in the Troposphere (MOPITT - Drummond et al., 2010, 2016; abbreviations are defined in Appendix A) instrument is one of a large fleet of satelliteborne instruments capable of observing the composition of the Earth's atmosphere from space. The target gas for MOPITT is carbon monoxide (CO), which is emitted from a 
range of anthropogenic (e.g. fossil fuel use) and natural (e.g. wildfires) sources, produced via the oxidation of methane and other volatile organic compounds, and has an atmospheric lifetime of weeks to months depending on season and location (e.g. Duncan et al., 2007). CO is therefore vital to monitor as a pollutant in its own right, as a tracer of local and transported pollution sources, and also because it plays an important role in atmospheric chemistry, i.e. as a precursor to ozone formation and a primary sink for the hydroxyl radical. While multiple sensors observe $\mathrm{CO}$ (see e.g. Worden et al., 2013, for a comparison of CO trends from four satellite instruments), the unique strength of MOPITT lies in its nearly unbroken record of observations since launch in December 1999. This makes MOPITT data very valuable for the analysis of temporal trends in $\mathrm{CO}$ concentrations (e.g. He et al., 2013; Worden et al., 2013; Strode et al., 2016).

MOPITT retrieves coarse-vertical-resolution $\mathrm{CO}$ profiles in the troposphere by inverting observed upwelling radiances at thermal infrared (TIR) and near-infrared (NIR) wavelengths (Deeter et al., 2013). These profiles are integrated to give $\mathrm{CO}$ total column amounts (TCO). In addition to several other inputs, MOPITT's optimal estimation retrieval algorithm requires a priori information - among which is a description of the most probable state of the $\mathrm{CO}$ profile and its variability - to obtain physically realistic results (Pan et al., 1998; Rodgers, 2000; the retrieval algorithm is outlined in more detail in Sect. 2.1.1). The proportion of information about $\mathrm{CO}$ concentrations in each individual retrieval that comes directly from the satellite measurement, as opposed to the a priori, is highly variable. It depends on scene-specific factors such as surface temperature, thermal contrast in the lower troposphere, and the actual (true) CO loading itself, as well as on instrumental noise (e.g. Deeter et al., 2015). This complicates the interpretation of retrievals, thus placing great importance on the analysis of retrieval averaging kernels (AKs), which represent the sensitivity of each retrieved profile point to the true $\mathrm{CO}$ profile and quantify the overall information content of the retrieval (as described in detail by e.g. Deeter et al., 2007 and 2015 as well as Rodgers, 2000). The lower the retrieval information content, the closer the retrieved CO loading will be to the a priori, which is based on a climatological model value. Retrievals with little information content should thus be treated with caution in any analysis.

In general, the greatest information content is associated with daytime retrievals over land, during the summer season (MOPITT Algorithm Development Team, 2017; Deeter et al., 2015). This is where and when thermal contrast conditions are typically greatest, maximizing the instrument's ability to sense $\mathrm{CO}$ absorption in the lowermost layers of the troposphere against the hot surface emission background (Deeter et al., 2007; Worden et al., 2010). To ensure that analyses involving MOPITT data are not biased by retrievals that have a heavy reliance on the a priori (in other words, a low information content), it is therefore suggested that users of MOPITT data consider excluding from analysis retrievals obtained during winter months, over water, and also from certain other geographical areas where retrieval information content is known to be low, i.e. over mountainous regions, where the effects of geophysical noise reduce information content relative to flatter terrain (MOPITT Algorithm Development Team, 2017; Deeter et al., 2015). Deeter et al. (2015) specifically emphasizes such filtering in the analysis of longterm CO trends, since inclusion of retrievals with a heavy a priori weighting will weaken any real trends in the data. This occurs because the a priori $\mathrm{CO}$ is based on monthly climatologies of modelled $\mathrm{CO}$ amounts and is therefore variable by month but not by year (Deeter et al., 2014).

MOPITT data are available as Level 2 (L2) products, where each individual retrieval at $22 \mathrm{~km} \times 22 \mathrm{~km}$ spatial resolution is available for analysis; and Level 3 (L3) products, which are a $1^{\circ} \times 1^{\circ}$ area-averaged version of the individual L2 retrievals that fall within each grid box (with some filtering criteria applied - see Sect. 2.1.2). At the heart of this study is the fact that some L3 grid boxes straddle the coastline. L3 products for such grid boxes can therefore be based on L2 retrievals over both land and water (see Fig. 1), the information content of which can differ greatly (e.g. Deeter et al., 2007). In this study, we demonstrate, for a coastal L3 grid box, how well-known and well-characterized differences in retrieval sensitivity over land and water can lead to significant differences in the $\mathrm{L} 2$ retrieved profiles that are averaged together to create the L3 products (Sect. 3.1). We outline the impact that this has on the statistics of the resulting L3 CO profiles, and we demonstrate the consequences that it has for temporal trend analysis with the L3 dataset, when compared to the results of the same analysis applied to the underlying L2 data that can be filtered by surface type to maximize information content (Sect. 3.2). This is an important issue to be aware of for two reasons: firstly, owing to their smaller file size, L3 data are better suited to long time series analysis than L2 data $(\sim 25 \mathrm{MB}$ vs. $\sim 450 \mathrm{MB}$ respectively, for a single daily, global file). Working with L3 data requires fewer computing resources and, arguably, less technical expertise, making the MOPITT data more readily accessible to a greater number of users who are potentially less well positioned to scrutinize the data. Secondly, 6 of the top 10 and 43 of the top 100 largest agglomerations by population in the world (population data taken from http://www.citypopulation.de/, last access: 11 June 2020) lie within a coastal L3 grid box, and it is such cities that are likely to be targets for analyses of temporal trends in air quality indicators. The results that we report here suggest that similar analyses be performed for other coastal cities before using MOPITT surface CO.

This paper is structured as follows: in Sect. 2 we outline the data and methods used in this study, giving an overview of the MOPITT instrument, retrieval, and surface type classification that is relevant to our work. In Sect. 3 our results are presented and discussed, and conclusions are drawn in Sect. 4. 
(a)

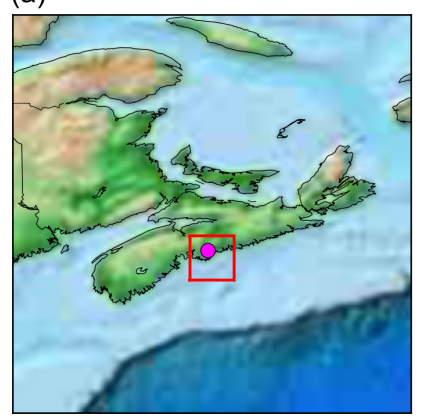

(b)

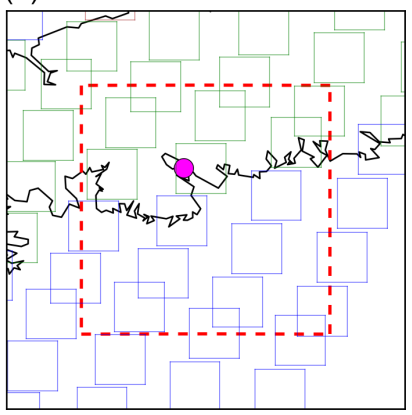

Figure 1. (a) Map of Nova Scotia and the surrounding region in Atlantic Canada. Lighter colours on land indicate higher elevation. The pink dot shows the location of Halifax, the coastal city that we focus on in this study (see Sect. 2.1.3), and the red box shows the MOPITT L3 $1^{\circ} \times 1^{\circ}$ grid box containing Halifax. (b) Map zoomed to the MOPITT L3 grid box containing Halifax (red dashed box), with the approximate location of individual L2 retrieval footprints shown (blue boxes represent the L2 surface index of water; green boxes represent the L2 surface index of land). L2 retrieval footprints with a midpoint that falls within the boundaries of the L3 grid box will be averaged together to create the L 3 data, according to certain rules - see Sect. 2.1.2 for full explanation.

\section{Data and methods}

\subsection{MOPITT}

\subsubsection{Instrument and retrieval overview}

MOPITT has been making routine observations almost continuously since March 2000. It is carried on board the polarorbiting NASA Terra satellite, with a nominal altitude of $\sim 705 \mathrm{~km}$ and an equatorial overpass time of $\sim 10: 30$ and $\sim 22: 30$ local time. The instrument is a nadir-viewing gas correlation radiometer, with a ground resolution of $22 \mathrm{~km} \times$ $22 \mathrm{~km}$. It observes radiances in two CO-sensitive spectral bands: the TIR at $4.7 \mu \mathrm{m}$ and the NIR at $2.3 \mu \mathrm{m}$. The TIR band is sensitive to both absorption and emission by $\mathrm{CO}$ and yields information on its vertical distribution in the troposphere (Pan et al., 1995, 1998). The NIR band measures reflected solar radiation, which constrains the $\mathrm{CO}$ total column amount and yields information on $\mathrm{CO}$ concentrations in the lower troposphere (LT), to which TIR radiances are typically less sensitive (Pan et al., 1995, 1998). NIR radiances can, however, only be exploited in daytime scenes over land. Our results are based on analysis of the TIR-NIR combined product, owing to its greater sensitivity to LT CO compared to the TIR- and NIR-only products which are also available (e.g. Deeter et al., 2017). Owing to the increased LT sensitivity from NIR radiances being limited to retrievals over land, we expect that the results presented here show an upper bound on (i) the retrieval differences between surface types within our coastal L3 grid box of focus and (ii) the consequent effects on sample statistics and temporal trends that we outline.
Differences are still found in the TIR-only product, however, and we outline these in Sect. S1 in the Supplement. We restrict our analysis to daytime-only retrievals (more information on data selection in Sect. 2.1.3).

Multiple other sources describe MOPITT's CO retrieval algorithm in detail (e.g. Deeter et al., 2003; Francis et al., 2017). Briefly, it employs optimal estimation (Pan et al., 1998; Rogers, 2000) and a fast radiative transfer model (Edwards et al., 1999) to invert radiance measurements performed by the instrument to obtain $\mathrm{CO}$ concentrations. Additional inputs required include meteorological data (profiles of temperature and water vapour), surface temperature and emissivity, and satellite viewing geometry for the radiative transfer model, as well as a priori CO profiles to constrain the inversion to physically reasonable limits. For latest MOPITT product versions, meteorological fields are extracted from the NASA Modern-Era Retrospective Analysis for Research and Applications Version 2 (MERRA-2) reanalysis product; and a priori $\mathrm{CO}$ profiles are derived from a monthly $\mathrm{CO}$ climatology for the years 2000-2009, simulated with the Community Atmosphere Model with Chemistry (CAM-chem) chemical transport model at a spatial resolution of $1.9^{\circ} \times 2.5^{\circ}$ (Lamarque et al., 2012) and then spatially and temporally interpolated to the time and location of the MOPITT observation. As it is a multi-year climatology, the a priori features no yearly trend; i.e. values for a given location and day of the year are the same every year. Surface temperature and emissivity values are retrieved from the radiance measurements (the retrieval also requires a priori information for these measurements). Retrievals are only performed for cloud-free scenes, with cloud screening based on collocated Moderate Resolution Imaging Spectroradiometer (MODIS) observations and MOPITT's own radiances. CO profiles are retrieved on 10 vertical levels, with 9 equally spaced pressure levels from 900 to $100 \mathrm{hPa}$ (the uppermost level covers the atmospheric layer from 100 to $50 \mathrm{hPa}$ ) and a floating surface pressure level. Where the surface pressure is below $900 \mathrm{hPa}$, less than 10 profile levels are retrieved. Reported values represent the mean $\mathrm{CO}$ volume mixing ratio (VMR) in the layer immediately above that level. Retrievals are initially performed on a $\log _{10}$ (VMR) scale, owing to large CO variability in the atmosphere.

Averaging kernels are produced for each retrieval and distributed with the data. The AK matrix (A) quantifies the sensitivity of the retrieved vertical profile to the true vertical profile and depends on the radiance weighting functions, instrument error covariance matrix, and a priori covariance matrix. Its relationship to the retrieved profile $\left(\boldsymbol{X}_{\mathrm{rtv}}\right)$, the true profile ( $\left.\boldsymbol{X}_{\text {true }}\right)$, and the a priori profile ( $\left.\boldsymbol{X}_{\text {apr }}\right)$ is expressed as follows (e.g. Deeter et al., 2017):

$\boldsymbol{X}_{\mathrm{rtv}}=\boldsymbol{X}_{\mathrm{apr}}+\mathbf{A}\left(\boldsymbol{X}_{\text {true }}-\boldsymbol{X}_{\text {apr }}\right)$.

Thorough analysis of AKs is essential for understanding the physical significance of MOPITT's CO retrievals. We discuss AKs in more detail in Sect. 3.1.2. 
The MOPITT retrieval algorithm is subject to continuous development, in line with improvements in understanding of the changing instrumental characteristics and geophysical factors that affect the retrieval sensitivity, and with periodic updates to the radiative transfer model (Worden et al., 2014). This prompts the release of new product versions, with enhanced validation statistics against in situ $\mathrm{CO}$ observations. The work presented in this paper is based on MOPITT Version 7 (V7) products (Deeter et al., 2017). We analyse both L2 and L3 products (as outlined below). It should be noted that MOPITT Version 8 products have been released very recently, incorporating an improved radiance bias correction method to address a documented drift and geographical variability in retrieval bias compared to in situ measurements (Deeter et al., 2019). It remains to be seen whether the impacts of land-water retrieval sensitivity contrasts documented in this study remain in this newest product version.

\subsubsection{Surface type classification}

Both L2 and L3 data files come with a range of diagnostic fields and values, in addition to the averaging kernel matrix, that can be used for filtering and interpreting retrievals. Of particular importance is the surface index flag. Because retrieval information content is variable depending on surface type (Deeter et al., 2007), each L2 retrieval is tagged according to whether it was performed over land, water, or a combination of the two (mixed). The surface index of each L3 grid box is then based on the L2 retrievals that fall within the relevant $1^{\circ} \times 1^{\circ}$ grid boundaries (Fig. 1). Where more than $75 \%$ of the bounded L2 retrievals have the same surface index, only those retrievals are used to produce the L3 gridded value (the other $\mathrm{L} 2$ retrievals are discarded), and the L3 surface index is set to that surface type. Otherwise, all L2 retrievals available in the L3 grid box are averaged together and the L3 surface index is set to mixed (this information is taken from the MOPITT Version $6 \mathrm{~L} 3$ data quality summary ${ }^{1}$ - at the time of writing, no V7 L3 data quality summary was available).

The averaging together of retrievals with significantly different sensitivity profiles - as could be the case when averaging retrievals over land and water - serves to dilute the information coming from the MOPITT observed radiances with information coming from the a priori, thus increasing the dependence of the resulting $\mathrm{CO}$ profile values on the a priori profile. In fact, guidelines to maximize the information content of MOPITT data and minimize the influence of the a priori are to restrict analysis to daytime observations over land during the summer season, since this is when thermal contrast conditions are greatest, thus maximizing the instrument's ability to sense $\mathrm{CO}$ in the lowermost layers of the troposphere (MOPITT Algorithm Development Team, 2017;

\footnotetext{
${ }^{1}$ Available at https://eosweb.larc.nasa.gov/sites/default/files/ project/mopitt/quality_summaries/mopitt_level3_ver6.pdf (last access: 11 June 2020).
}

Deeter et al., 2015, 2007). Unfortunately, such filtering does lead to an overall loss of available retrievals for analysis, reducing the effective temporal and spatial coverage of the data.

\subsubsection{Study area, time period, and MOPITT data processing in this study}

Our analysis is based on MOPITT retrievals over the city of Halifax in Nova Scotia, Canada (Fig. 1: longitude $-63.58^{\circ}$, latitude $44.65^{\circ}$ ). Situated on the Atlantic coastline, Halifax is the major economic centre in Atlantic Canada, with a population in excess of 315000 in the urban core of Halifax Harbour (from 2016 census statistics). The pollution environment of Halifax, which is an intermediate port city, was characterized in detail by Wiacek et al. (2018 - trace gases of focus include $\mathrm{SO}_{x}, \mathrm{CO}_{2}, \mathrm{CO}, \mathrm{NO}_{x}, \mathrm{O}_{3}, \mathrm{HC}$, and $\mathrm{PM}$ ); briefly, it showed no exceedances of regulated gaseous contaminants, but nevertheless a substantial contribution of shipping emissions that is comparable to or greater than emissions from the city's vehicle fleet and a nearby $500 \mathrm{MW}$ power plant. All available MOPITT V7 L2 and L3 TIRNIR files (MOP02J and MOP03J files, respectively) were downloaded from the NASA Earthdata portal (https://search. earthdata.nasa.gov, last access: 11 June 2020). There is a small inconsistency in the data record before and after an instrumental reconfiguration in 2001 (Drummond et al., 2010); we therefore discard all data prior to this reconfiguration. The remaining data covers the period 25 August 2001 to 5 March 2017. At the time of writing, more recent data are flagged as beta files, which await a future retrospective processing after the annual hot calibration becomes available, and their use in scientific analyses is discouraged (Deeter et al., 2017). For clarity and brevity, we restrict our main analyses and discussion to the winter (DJF) and summer (JJA) seasons, since these best encapsulate the different thermal contrast conditions over land and water, when compared to the intermediate (MAM and SON) seasons. For completeness, we demonstrate that our findings also hold for MAM and SON in Sect. 3.3.

We extract L3 data for the $1^{\circ} \times 1^{\circ}$ grid box that contains the city of Halifax, and retain only the observations that were made during daytime hours. This yields a time series with one observation per day, when retrieval data were available within this grid box. There are no retrievals available on $91 \%$ of all days in DJF and $83 \%$ of all days in JJA for the period covered. This is a result of both (1) MOPITT's polar orbit limiting temporal resolution to $\sim 3 \mathrm{~d}$ over most of the globe; and (2) on days when the satellite's swath does encompass Halifax, retrievals either not being made due to cloud coverage, or discarded due to data quality issues. While this does not prevent a meaningful comparison of available retrievals, it does mean that caution is needed when using them to draw conclusions about the time period covered as a whole, which is something that we do not attempt to do. For clarity, we re- 
Table 1. (a) Surface classification of L3 data for the $1^{\circ} \times 1^{\circ}$ grid box containing Halifax (L3O) for the period 25 August 2001 to 5 March 2017. Note that no retrievals are available for this L3 grid box on $91 \%$ of days in DJF and $83 \%$ of days in JJA. (b) Mean number of individual L2 retrievals with land and water surface index that contribute to the $\mathrm{L} 3 \mathrm{~L}$ and $\mathrm{L} 3 \mathrm{~W}$ time series, respectively (the standard deviation is in brackets).

\begin{tabular}{lcccc|cc}
\hline Season & \multicolumn{4}{c|}{ (a) } & \multicolumn{2}{c}{ (b) } \\
\hline & Water & Land & Mixed & Total & L3L & L3W \\
\hline DJF & 101 & 1 & 23 & 125 & $1.7( \pm 1.1)$ & $4.0( \pm 1.7)$ \\
JJA & 136 & 1 & 98 & 235 & $2.1( \pm 1.2)$ & $4.1( \pm 1.8)$ \\
\hline
\end{tabular}

fer to the original, as-downloaded L3 time series as L3O for the remainder of this paper, owing to the way that we process the L2 data (explained below). Because this grid box straddles the coastline, the $\mathrm{L} 3 \mathrm{O}$ surface index varies each day. The surface classification breakdown of the L3O time series is given in Table 1a. "Water" is the modal classification in both seasons, followed by "mixed". L3O is only classified as "land" on one occasion each season. This is most likely due to the fact that more of the L3 grid box is situated over water than land (Fig. 1). The ratio of water to mixed observations is far greater in DJF than in JJA. This may be due to preferential cloud coverage over land in winter and/or could be linked to the misidentification of snow/ice coverage on the surface as cloud during cloud screening (identifying the exact cause for this difference is beyond the scope of this paper).

We select all L2 retrievals that fall within the $1^{\circ} \times 1^{\circ} \mathrm{L} 3$ grid box that contains the city of Halifax (lower-left corner: $-64^{\circ} \mathrm{E}, 44^{\circ} \mathrm{N}$; upper-right corner: $-63^{\circ} \mathrm{E}, 45^{\circ} \mathrm{N}$ ). Because we directly compare the $\mathrm{L} 2$ retrievals to the $\mathrm{L} 3$ product that they create, we filter these based on pixel number (each pixel corresponds to one of MOPITT's four along-track detectors) and channel-average signal-to-noise ratio (SNR), as is done at the V7 L3 processing stage to improve L3 information content by excluding observations from specific detector elements on MOPITT's detector array that were found to exhibit greater retrieval noise than the other elements (MOPITT Algorithm Development Team, 2017; Deeter et al., 2017). Specifically, these filters exclude the following: all observations for pixel 3 and all observations where both (1) the channel 5A SNR $<1000$ and (2) the channel 6A SNR $<400$. Channels $5 \mathrm{~A}$ and $6 \mathrm{~A}$ correspond to the average radiances for MOPITT's length-modulated cell TIR and NIR channels, respectively. Finally, we only retain daytime retrievals, using a solar zenith angle filter of $<80^{\circ}$.

From this subset of $\mathrm{L} 2$ retrievals, we take separate area averages for those with a surface index of land and water, creating two time series that are effectively new L3 land-only and water-only products, for days when MOPITT retrievals over Halifax are available. We herein refer to these as L3L and L3W, respectively. For clarity of analysis, we discard remaining L2 retrievals with a surface index of mixed (these account for $\sim 5 \%$ of the total $\mathrm{L} 2$ retrieval subset). The number of individual $\mathrm{L} 2$ retrievals that are averaged together each day to create L3L and L3W is given in Table 1b. From this, it is clear that there are around double the number of $\mathrm{L} 2$ retrievals over water than land within the L3 grid box containing Halifax, which explains the dominance of water in the L3O surface classification (Table 1a) and also means that L2 retrievals over water will have a greater weighting in $\mathrm{L3O}$ than $\mathrm{L} 2$ retrievals over land on days when the surface index is mixed.

\subsection{Retrieval simulation}

To demonstrate how MOPITT retrieved CO concentrations are affected by retrieval sensitivity (Sect. 3.1.3), we simulate pairs of L3L and $\mathrm{L} 3 \mathrm{~W}$ retrieved profiles that are obtained concurrently (i.e. retrieved on the same day - on some days, one of $\mathrm{L} 3 \mathrm{~L}$ or $\mathrm{L} 3 \mathrm{~W}$ is missing) as follows:

$\boldsymbol{X}_{\mathrm{sim}}=\boldsymbol{X}_{\mathrm{apr}, \operatorname{sim}}+\mathbf{A}\left(\boldsymbol{X}_{\mathrm{tr}, \mathrm{sim}}-\boldsymbol{X}_{\mathrm{apr}, \operatorname{sim}}\right)$.

For each simulated retrieval, $\boldsymbol{X}_{\mathrm{tr}, \mathrm{sim}}$ is taken from the Copernicus Atmospheric Monitoring Service (CAMS) reanalysis (CAMSRA - see Sect. 2.3), for the model grid box that contains Halifax, for the corresponding month and year of the observed retrieval (because the CAMSRA data are monthly mean values); $\boldsymbol{X}_{\mathrm{apr}, \mathrm{sim}}$ is the mean of the a priori fields that correspond to the temporally coincident $\mathrm{L} 3 \mathrm{~L}$ and $\mathrm{L} 3 \mathrm{~W}$ pairings; and $\mathbf{A}$ is the retrieval averaging kernel from L3L or L3W. Thus, any differences between each pair of simulated retrievals ( $\boldsymbol{X}_{\text {sim, L3L }}$ and $\left.\boldsymbol{X}_{\text {sim, L3W }}\right)$ are solely a result of differences in $\mathbf{A}$, since $\boldsymbol{X}_{\mathrm{tr}, \text { sim }}$ and $\boldsymbol{X}_{\mathrm{apr}, \text { sim }}$ are identical for both. Simulations are initially performed on $\log _{10}$ (VMR) for consistency with the MOPITT retrieval algorithm and then converted back to VMR scale for analysis.

\subsection{Additional datasets}

The CAMSRA dataset to simulate retrievals is described by Inness et al. (2019). For the CAMSRA grid box containing Halifax (horizontal resolution is $1^{\circ} \times 1^{\circ}$ ), we extract $\mathrm{CO}$ volume mixing ratios for levels $1000-100 \mathrm{hPa}$ at $100 \mathrm{hPa}$ intervals, which correspond to the MOPITT levels of the profile. The CAMSRA dataset has no surface level, so we take the $1000 \mathrm{hPa}$ level (the lowest level available in the dataset) to correspond to MOPITT's floating surface level. At the time of writing, CAMSRA data are only available for the years 2003-2016.

Information on mean wind patterns across Nova Scotia and the surrounding area is taken from the European Centre For Medium-Range Weather Forecasts (ECMWF) ERAInterim dataset (horizontal resolution is $0.75^{\circ} \times 0.75^{\circ}$; see Dee et al., 2011, for a dataset overview). We analyse daily mean $\boldsymbol{u}$ and $\boldsymbol{v}$ vector winds for the following levels: $10 \mathrm{~m}$ (the closest level to the surface for winds in the dataset) and 850 and $500 \mathrm{hPa}$ (which correspond roughly to the lower- 
and mid- troposphere, respectively). In addition, we extract monthly mean temperature profile data (at $100 \mathrm{hPa}$ intervals, plus the skin temperature and $2 \mathrm{~m}$ air temperature variables) for the closest model grid boxes to Halifax that exclusively cover land and ocean, in order to illustrate the typical landonly and water-only temperature profiles that correspond to the MOPITT L2 retrievals over land and water that are analysed.

\section{Results and discussion}

\subsection{Impact of retrieval sensitivity differences on temporally coincident $\mathrm{L} 3 \mathrm{~L}$ and $\mathrm{L} 3 \mathrm{~W}$ retrievals}

In this section we compare the $\mathrm{L} 3 \mathrm{~L}$ and $\mathrm{L} 3 \mathrm{~W}$ CO retrievals and demonstrate where and when there are differences in retrieved CO concentrations that are clearly linked to differences in retrieval sensitivity over land and water. We restrict our analysis to days when the L3O surface index is mixed and both $\mathrm{L} 3 \mathrm{~L}$ and $\mathrm{L} 3 \mathrm{~W}$ retrievals are present, in order to minimize any potential differences in the true profile between land and water (there are a couple of days in the L3O time series when one or the other of $\mathrm{L} 3 \mathrm{~L}$ or $\mathrm{L} 3 \mathrm{~W}$ is missing, even when the $\mathrm{L} 3 \mathrm{O}$ surface index is mixed, owing to the presence of L2 retrievals with a surface index of mixed, which we have discarded). Thus, an underlying assumption here is that landwater differences in the true profile for retrievals contributing to $\mathrm{L} 3 \mathrm{~L}$ and $\mathrm{L} 3 \mathrm{~W}$ are small, owing to the fact that they are retrieved in close spatial proximity to each other (i.e. within the same $1^{\circ} \times 1^{\circ}$ grid box) and at the same time. We test this assumption in Sect. 3.1.4 and 3.1.5.

\subsubsection{Climatology of land-water retrieval and a priori differences}

Figure 2 shows the percentage difference between temporally coincident retrieved VMRs for selected levels of the profile and for CO total column (TCO) amounts ( $\triangle$ RET) in L3L and L3W. Positive (negative) differences indicate that retrieved VMRs/TCO are greater (less) in L3W than L3L. Differences are expressed as percent values, rather than differences in measurements units, so that we can display profile and TCO retrievals on the same plot (profile units are ppbv, and TCO units are molecules $\mathrm{cm}^{-2}$ ).

In both seasons, mean retrieved VMRs are greater in L3W than L3L in the lower troposphere (LT - surface, 900 and $800 \mathrm{hPa}$ levels), with a maximum mean difference of $11.6 \%$ (14.3 ppbv) at the surface level in JJA, the only profile location where the mean difference is significant $(p=0.001)$. The spread of $\triangle$ RET values is comparable in both seasons at these levels, with a clear skew towards positive values. Thus, although retrieved LT VMRs in L3L may occasionally exceed those in L3W by over $20 \%$, they are usually greater over water than land. Mean $\triangle$ RET values are closer to zero and less significant in the MT and UT (represented by the 600 and $300 \mathrm{hPa}$ profile levels respectively), indicating that differences in retrieved VMRs are not as persistent at higher altitudes. However, the spread in $\triangle$ RET remains large at these altitudes, with retrieved VMRs in L3L and L3W differing by over $\pm 40 \%$ on individual days (with outliers exceeding $\pm 60 \%$ ). TCO is greater in L3W than L3L in both seasons, significantly so in JJA. This is consistent with the most persistent VMR differences occurring in the LT, where atmospheric densities are greatest, thus contributing a relatively greater amount to the total column than MT and UT levels.

Our assumption in this section is that $\mathrm{L} 2$ retrieved $\mathrm{CO}$ concentrations obtained within the same $1^{\circ} \times 1^{\circ} \mathrm{L} 3$ grid box should be similar. We may actually expect retrieved $\mathrm{CO}$ amounts in L3L to be greater than those in $\mathrm{L} 3 \mathrm{~W}$ due to $\mathrm{CO}$ sources existing on land, particularly within the city of Halifax. One reason for the $\triangle$ RET values instead indicating higher concentrations over water could be differences in the a priori profiles ( $\triangle \mathrm{APR}$ ) used in the corresponding retrievals. The $\mathrm{L} 2$ retrievals over land and water have different a priori profiles owing to spatial interpolation of the $1^{\circ} \times 1^{\circ}$ model climatology to the $22 \mathrm{~km} \times 22 \mathrm{~km}$ footprint of the MOPITT L2 retrieval. However, as Fig. 2 demonstrates, $\triangle$ APR values are small in comparison to $\triangle$ RET, with mean difference values very close to zero and a maximum range of $10.4 \%$ (occurring at the surface level in JJA). Moreover, the sign of mean $\triangle$ APR does not match that of mean $\triangle$ RET at several levels in both seasons (i.e. retrieved VMRs in L3W are greater than in L3L, but a priori VMRs are less). It therefore appears unlikely that a priori profile differences are responsible for the observed differences in retrieved $\mathrm{CO}$ concentrations in $\mathrm{L} 3 \mathrm{~L}$ and $\mathrm{L} 3 \mathrm{~W}$.

\subsubsection{Climatology of land-water retrieval sensitivity differences}

An alternative explanation for the observed $\triangle$ RET could be differences in retrieval sensitivity over land and water, quantified by the retrieval AK matrix. Figure 3 compares the mean AKs corresponding to the retrieved profiles in $\mathrm{L} 3 \mathrm{~L}$ and $\mathrm{L} 3 \mathrm{~W}$ analysed in the previous section. Each curve corresponds to a row of the AK matrix and represents the sensitivity of the corresponding level of the retrieved profile to each level of the true $\mathrm{CO}$ profile, with the widest part of each $\mathrm{AK}$ in the $x$ direction (when a peak is evident) indicating the portion of the true profile that the corresponding level of the retrieved profile is most sensitive to. The sum of the elements in each AK row represents the overall sensitivity of the retrieved profile at the corresponding pressure level to the whole true profile; values close to zero indicate that the retrieval is relatively insensitive to the true profile and therefore closely tied to the a priori profile, while the converse is true as the rowsum approaches one. The mathematical trace of the AK matrix (i.e. sum of the diagonals) gives the degrees of freedom for signal (DFS) of the retrieval, which is a measure of the number of independent pieces of information (in other words, infor- 

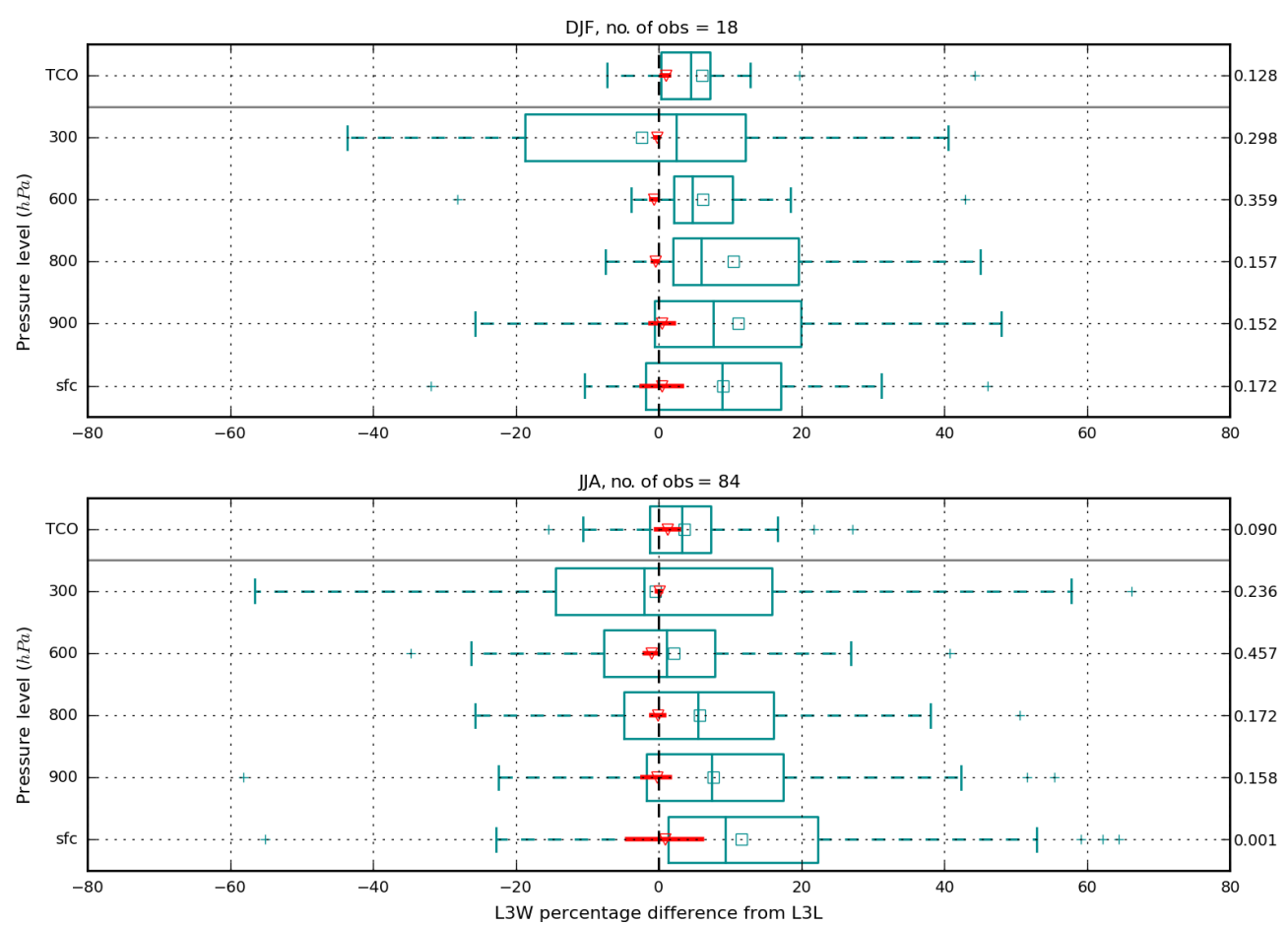

Figure 2. Distribution of percentage difference (method for calculating percentage differences: $\left.\left\{\left(\frac{\mathrm{L} 3 \mathrm{~W}}{\mathrm{~L} 3 \mathrm{~L}}\right) \cdot 100\right\}-100\right)$ between temporally coincident retrieved VMRs (selected profile levels) and CO total column (TCO) from L3W and L3L. Squares represent mean differences, with the $p$ value associated with each mean difference (from a two-tailed Student $t$ test) given on the right-hand-side $y$ axis. Plus symbols represent outliers (outliers defined as above (below) percentile $75(25)+(-) 1.5 \cdot$ interquartile range). Red triangles represent the mean percentage difference between a priori values. Red lines represent the range of a priori difference values (where barely visible this means range is very small).

mation content) in the retrieval from the measurement, with respect to the true profile. When DFS values approach two, this is interpreted as the retrieval being able to resolve $\mathrm{CO}$ in two independent atmospheric layers.

There are some clear differences between the mean AKs over land (from L3L) and water (from L3W) shown in Fig. 3. In DJF, AKs for LT (especially surface level) retrievals reach greater values in the $\mathrm{LT}$ in $\mathrm{L} 3 \mathrm{~W}$ than $\mathrm{L} 3 \mathrm{~L}$, indicating that sensitivity to the true profile at these levels is actually greater in L3W (surface level AK peak is 0.14 for water and 0.09 for land, both at the surface level). This is reflected in greater rowsum values for LT AKs in L3W than L3L. Differences in MT $(600 \mathrm{hPa})$ and UT $(300 \mathrm{hPa})$ AKs are much less pronounced, with sensitivity to the true profile actually becoming slightly greater in L3L than L3W higher up in the troposphere. In JJA, the mean LT and MT AKs are qualitatively much more different between L3L and L3W than in DJF. LT rowsums are significantly greater in L3L $(p<0.001$ at the surface, 900 and $800 \mathrm{hPa}$ profile levels; see Sect. S2) and closer to one, signifying that these retrievals contain much more true profile information than those in L3W. The AK shapes also indicate that the respective retrievals are sensitive to different parts of the true profile. In L3L, surface and LT AKs peak at either the surface (surface level AK) or at
$900 \mathrm{hPa}$ (both the 900 and $800 \mathrm{hPa}$ level AKs) and decline towards the UT, while MT AKs indicate relatively equal sensitivity throughout the LT, MT and the lower levels of the UT. In L3W on the other hand, LT and MT AKs (excluding the largely insensitive surface level) indicate relatively little sensitivity in the lowest profile levels and peak in the MT. The surface level AK in L3W actually indicates close to zero sensitivity throughout the profile, aside from a very weak peak at the surface level, which is around 3 times lower than that over land. As in DJF, UT AKs are quite similar, except for relatively small differences at the surface, where the $300 \mathrm{hPa}$ AK over land actually indicates negative sensitivity. Differences in mean DFS values for retrievals in L3L and L3W are greater in JJA $(-0.12)$ than DJF (0.07), highlighting the greater land-water sensitivity contrast in JJA and also reflecting the switch in surface type exhibiting the greatest LT retrieval sensitivity between the seasons.

The differences in surface and LT AKs for MOPITT retrievals in L3L and L3W discussed above can be accounted for primarily by the differing LT thermal contrast conditions over land and water, as explored in detail by Deeter et al. (2007). The sensitivity of MOPITT retrievals to CO in the LT is predominantly controlled by the thermal contrast between the surface skin temperature $\left(T_{\text {skin }}\right)$ and the surface 

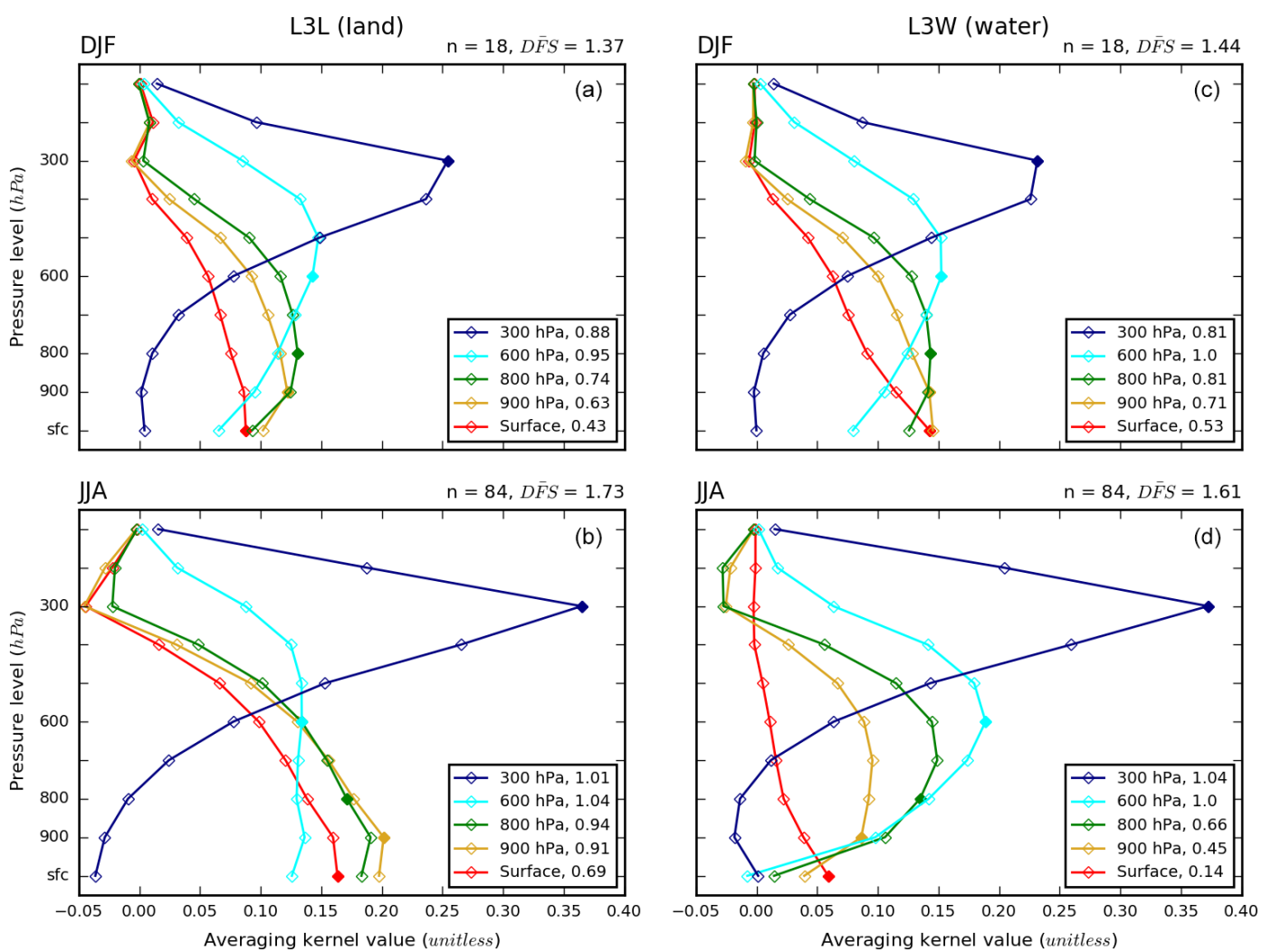

Figure 3. Mean retrieval averaging kernel (AK) rows and DFS values for L3L (land, a, b) and L3W (water, c, d) in DJF (a, c) and JJA (b, d), for selected profile levels only. Filled diamonds indicate the diagonal value location for that AK. Numbers in legend indicate the corresponding retrieval level of $\mathrm{AK}$ and show the mean rowsum for that $\mathrm{AK}$ level.

air temperature $\left(T_{\mathrm{sfc}}\right)$, as well as by the tropospheric temperature profile. Seasonal mean temperature profile data from ERA-Interim for the nearest land-only and water-only model grid boxes to Halifax show clear differences in DJF and JJA (Fig. 4). In DJF, $T_{\text {skin }}$ is around $6^{\circ} \mathrm{K}$ warmer than the $2 \mathrm{~m}$ air temperature $\left(T_{2 \mathrm{~m}}\right.$, which we use as a proxy for $T_{\mathrm{sfc}}$ as this is the lowest model level) over water and a further degree warmer than the air at $1000 \mathrm{hPa}$, whereas the temperature gradient is weak/slightly inverted over land, with $T_{\text {skin }}$ less than a degree warmer than $T_{2} \mathrm{~m}$, which is actually slightly cooler than the air at $1000 \mathrm{hPa}$. Correspondingly, the lowest couple of retrieval levels indicate greater sensitivity to the surface and LT over water (in L3W) than land (in L3L) in DJF (Fig. 3). Temperature profiles converge towards the MT, as do AKs. In JJA on the other hand, there is a clear gradient between $T_{\text {skin }}$ and the overlying air on land, while the ocean surface is actually cooler than the air above, up to a height of $900 \mathrm{hPa}$. As a result, surface and LT sensitivity is greater in L3L than in L3W in JJA, with the sensitivity of retrievals in L3W approaching zero close to the surface owing to this inverted temperature profile. The $T_{\text {skin }}$ increase approaching $20 \mathrm{~K}$ between DJF and JJA likely also accounts for the relatively greater overall true profile sensitivity (indicated by DFS values) in JJA for L3L than in DJF for L3W. Since our analysis is conducted using the joint TIR-NIR product, it is important to bear in mind that the benefit of enhanced LT sensitivity due to the incorporation of NIR is limited to retrievals over land, so this will also have an impact on the AK differences presented above. However, a land-water retrieval sensitivity contrast of comparable magnitude to that presented here is also evident in the TIR-only product, reinforcing the primary role of thermal contrast differences (see Sect. S1).

That the retrieval sensitivity contrast between L3L and $\mathrm{L} 3 \mathrm{~W}$ is most pronounced in the LT is consistent with the finding that retrieved $\mathrm{CO}$ profiles in $\mathrm{L} 3 \mathrm{~L}$ and $\mathrm{L} 3 \mathrm{~W}$ show the greatest differences in the LT. Although mean retrieval sensitivity in L3L and L3W converges with altitude, differences do exist from day to day, but they are neither as large nor as skewed in favour of retrievals over land or water (depending on season) as in the LT (see Sect. S2), where there is a well-understood thermal contrast mechanism creating the systematic land-water sensitivity contrast. Likely causes for this could be day-to-day changes in atmospheric conditions (i.e. temperature or water vapour profiles), or random instrumental or retrieval noise. 

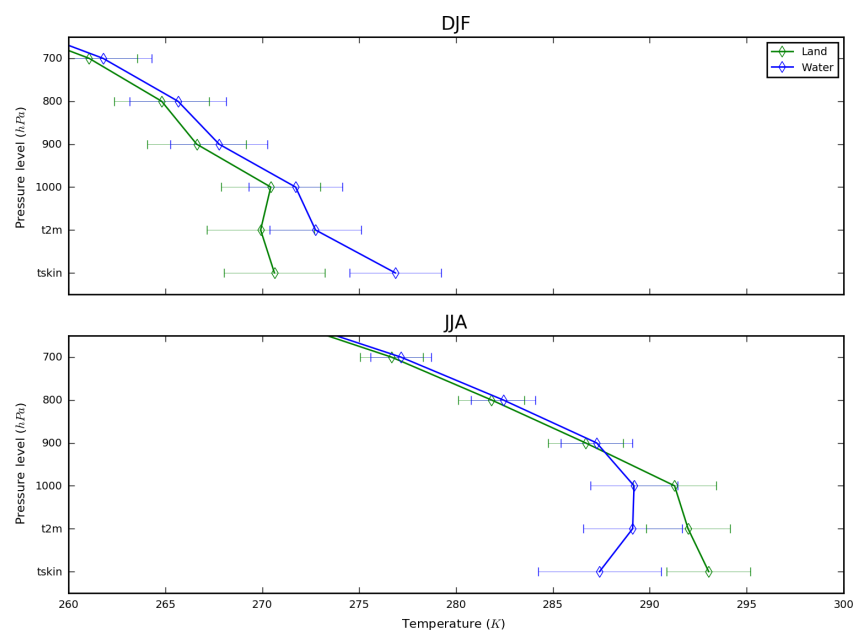

Figure 4. Mean temperature profile from ERA-Interim for the closest all-land and all-water model grid boxes to Halifax. Error bars show the standard deviation. Data are the mean of the 12:00 and 18:00 UTC time steps (this corresponds to 08:00 and 14:00 local time, the closest ERA-Interim time steps to the local MOPITT overpass time of 10:30) for 2001-2017.

\subsubsection{Control of $\triangle$ RET by land-water sensitivity differences}

To demonstrate that retrieval sensitivity differences over land and water can lead to the observed differences between $\mathrm{CO}$ profiles in $\mathrm{L} 3 \mathrm{~L}$ and $\mathrm{L} 3 \mathrm{~W}$ that are retrieved at the same time, we simulate and compare the pairs of retrieved $\mathrm{CO}$ profiles in $\mathrm{L} 3 \mathrm{~L}$ and $\mathrm{L} 3 \mathrm{~W}$ that are analysed in the preceding sections, using the transformation outlined in Sect. 2.2. Recall that any differences between each pair of simulated retrievals are solely a result of differences in AKs. Because available CAMSRA data only cover the years 2003-2016, only a subset of the retrieval pairings considered in earlier sections (which span the period 2001-2017) are simulated.

We first demonstrate the sensitivity effect with a case study on 18 August 2013. Profiles (a priori $\left(\boldsymbol{X}_{\mathrm{apr}, \mathrm{sim}}\right)$ and truth $\left.\left(\boldsymbol{X}_{\mathrm{tr}, \mathrm{sim}}\right)\right)$ and surface level AKs used in the simulation, and the resulting $\boldsymbol{X}_{\text {sim, L3L }}$ and $\boldsymbol{X}_{\text {sim, L3W, are given in Table } 2 .}$ For brevity, we only focus on the surface level. In this example, $\boldsymbol{X}_{\mathrm{tr}, \text { sim }}$ is considerably lower than $\boldsymbol{X}_{\mathrm{apr}, \text { sim }}$ at the surface level, and several features of the AKs indicate greater sensitivity to $\boldsymbol{X}_{\mathrm{tr}, \text { sim }}$ in L3L and L3W: the AK value is significantly greater at the surface in $\mathrm{L} 3 \mathrm{~L}$ than $\mathrm{L} 3 \mathrm{~W}$, and the rowsum is over 5 times as high. Correspondingly, $\boldsymbol{X}_{\text {sim, L3L }}$ is much lower than $\boldsymbol{X}_{\text {sim, L3W }}$ at the surface and much closer to $\boldsymbol{X}_{\text {tr, sim }}$ (32.21 ppbv higher vs. 57.13 ppbv higher). Both $\boldsymbol{X}_{\text {sim, L3L }}$ and $\boldsymbol{X}_{\text {sim, L3W }}$ indicate that $\boldsymbol{X}_{\text {tr, sim }}$ is lower than

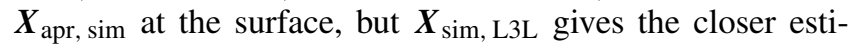
mate, as would be expected. In both cases, a portion of the overall departure from $\boldsymbol{X}_{\mathrm{apr}, \text { sim }}$ at the surface level (in other words, value added over the a priori) originates at other levels of the profile and not the surface level itself. This is a result of the surface level AK being nonzero at other levels and is a function of the inter-level correlation of the original retrieval, which is linked to the a priori covariance matrix used in the retrieval (Deeter et al., 2010).

We now consider differences between all $\boldsymbol{X}_{\text {sim, L3W }}$ and

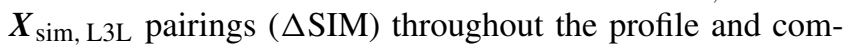
pare these to the observed differences between temporally coincident retrievals in L3L and L3W ( $\triangle$ RET) discussed previously (Fig. 5a). For ease of comparison, $\triangle$ RET values are overlaid (faint lines) for the shorter time period matching CAMSRA data availability (the 2003-2016 $\triangle$ RET patterns are very similar to those seen in Fig. 2). It should be noted that we cannot expect $\Delta$ SIM to match $\triangle$ RET exactly, owing to (possibly large) differences between the $\boldsymbol{X}_{\mathrm{tr}, \text { sim }}$ profiles used in the simulations and the (unknown) true profiles at the time of the actual MOPITT retrievals $\left(\boldsymbol{X}_{\text {true }}\right)$. For instance, $\boldsymbol{X}_{\mathrm{tr}, \operatorname{sim}}$ is a monthly mean value from a reanalysis model, whereas $\boldsymbol{X}_{\text {true }}$ varies by day, which should result in less variance in $\triangle$ SIM than $\triangle$ RET. In DJF, mean $\triangle$ SIM is negligible at all profile levels shown, and the range of values is far smaller than seen for $\triangle$ RET. In JJA on the other hand, $\triangle$ SIM reaches considerably larger values than in DJF, and mean values are significantly different $(p<0.05)$ over land and water at all but one level shown $(300 \mathrm{hPa})$. LT and MT $\Delta$ SIM distributions are a remarkably good match for $\triangle \mathrm{RET}$, given the likely substantial differences between $\boldsymbol{X}_{\text {tr, sim }}$ and $\boldsymbol{X}_{\text {true }}$. In the UT, $\Delta$ SIM values are somewhat smaller, although this is not unexpected given the smaller land-water AK differences evident in Fig. 3.

That L3L and L3W simulated and retrieved profile differences over land and water are comparable in JJA is clear evidence that $\triangle$ RET is strongly influenced by the land-water sensitivity contrast in summer months, at least in the LT. However, while $\triangle$ SIM values are of a much smaller magnitude in DJF than in JJA, $\triangle$ RET is actually of a similar magnitude in both seasons. The question therefore arises as to why $\triangle$ SIM is so different from $\triangle$ RET in DJF and why it is of much smaller magnitude in DJF than JJA. Considering the terms of Eq. (2), there are two possible explanations. Firstly, differences between L3L and L3W LT and MT AKs (A in Eq. 2) are much smaller in DJF than in JJA (Fig. 3). This means that the deviation of $\boldsymbol{X}_{\text {sim, L3W }}$ and $\boldsymbol{X}_{\text {sim, L3L }}$ from $\boldsymbol{X}_{\text {apr, sim }}$ will be more similar in DJF (resulting in small $\Delta \mathrm{SIM}$ ), as opposed to in JJA, where as was seen in the case study discussed above, $\boldsymbol{X}_{\text {sim, L3L }}$ can deviate more from

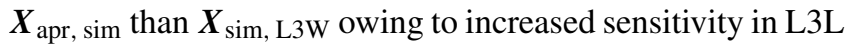
in the lower profile levels (resulting in greater $\Delta$ SIM than in DJF). In the UT, AK differences are comparable in both seasons, and $\Delta$ SIM is correspondingly similar. Secondly, the magnitude of $\boldsymbol{X}_{\mathrm{tr}, \text { sim }}-\boldsymbol{X}_{\mathrm{apr}, \text { sim }}$ from Eq. (2) is, on average, around 4 (3) times greater in JJA than in DJF at the surface $(900 \mathrm{hPa})$ level (Fig. 5b). $\boldsymbol{X}_{\text {sim, L3L }}$ therefore deviates more from $\boldsymbol{X}_{\text {apr, sim }}$ than $\boldsymbol{X}_{\text {sim, L3W }}$ throughout the LT and MT in JJA owing to strong contrasts in near-surface sensitivity at these profile levels, thus yielding large $\Delta$ SIM. Conversely, 
Table 2. Case study information for simulated L3L and L3W profile retrievals ( $\boldsymbol{X}_{\text {sim, L3L }}$ and $\boldsymbol{X}_{\text {sim, L3W }}$ respectively) for 18 August 2013. $\Delta=\boldsymbol{X}_{\mathrm{apr}, \mathrm{sim}}-\boldsymbol{X}_{\mathrm{tr}, \mathrm{sim}}$. Values that are italicized indicate the maxima (by magnitude) for that column. Simulated profile values for levels 900-100 $\mathrm{hPa}$ are shown in brackets because AKs and calculations for these levels are not discussed in the text and AKs for the $900-100 \mathrm{hPa}$ levels are not shown.

\begin{tabular}{lrrr|rr|rr}
\hline $\begin{array}{l}\text { Profile } \\
\text { level }\end{array}$ & \multicolumn{3}{c|}{ Input profiles } & \multicolumn{2}{c|}{$\begin{array}{c}\text { Surface level AK } \\
(==\mathbf{A}[1, i])\end{array}$} & \multicolumn{2}{|c}{$\begin{array}{c}\text { Simulated profiles } \\
\left(\boldsymbol{X}_{\text {sim }}\right)\end{array}$} \\
\cline { 2 - 9 } & $\boldsymbol{X}_{\text {apr, sim }}$ & $\boldsymbol{X}_{\text {tr, sim }}$ & $\Delta$ & L3W & L3L & $\boldsymbol{X}_{\text {sim, L3W }}$ & $\boldsymbol{X}_{\text {sim, L3L }}$ \\
\hline Surface & 188.81 & 128.45 & -60.36 & 0.01 & 0.23 & 185.58 & 160.67 \\
$900 \mathrm{hPa}$ & 148.88 & 119.53 & -29.34 & 0.03 & 0.20 & $(141.49)$ & $(124.02)$ \\
$800 \mathrm{hPa}$ & 118.07 & 109.80 & -8.27 & 0.02 & 0.15 & $(110.76)$ & $(100.25)$ \\
$700 \mathrm{hPa}$ & 102.72 & 97.64 & -5.08 & 0.03 & 0.14 & $(95.37)$ & $(88.72)$ \\
$600 \mathrm{hPa}$ & 95.49 & 90.34 & -5.15 & 0.03 & 0.12 & $(87.92)$ & $(83.64)$ \\
$500 \mathrm{hPa}$ & 92.00 & 87.10 & -4.91 & 0.03 & 0.08 & $(84.57)$ & $(82.57)$ \\
$400 \mathrm{hPa}$ & 89.64 & 83.85 & -5.78 & 0.02 & 0.02 & $(83.46)$ & $(84.12)$ \\
$300 \mathrm{hPa}$ & 84.76 & 81.42 & -3.34 & -0.01 & -0.07 & $(81.73)$ & $(83.91)$ \\
$200 \mathrm{hPa}$ & 64.45 & 65.20 & 0.75 & -0.01 & -0.04 & $(63.77)$ & $(64.75)$ \\
$100 \mathrm{hPa}$ & 26.51 & 28.71 & 2.20 & 0.00 & 0.00 & $(26.41)$ & $(26.52)$ \\
\hline
\end{tabular}
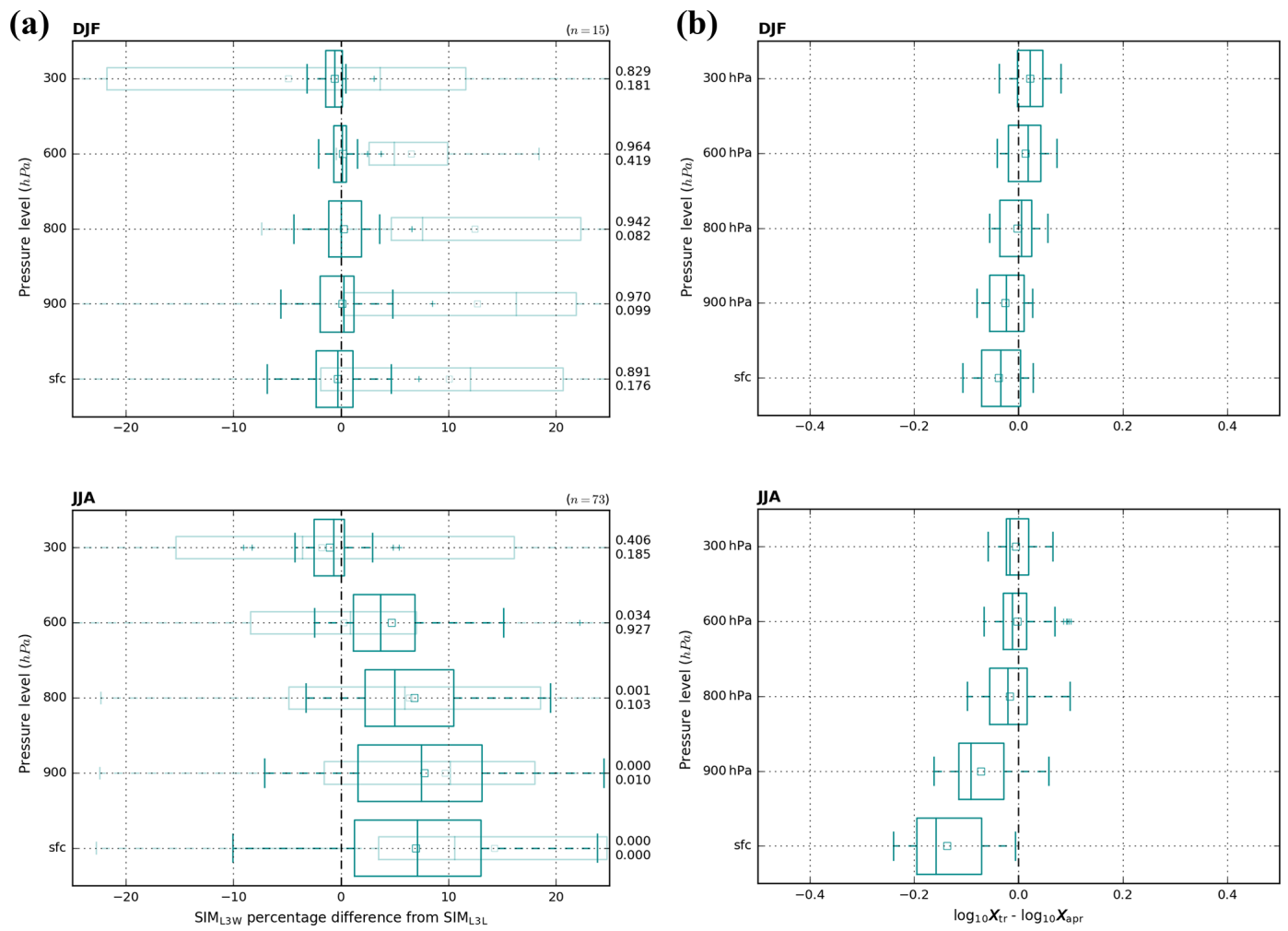

Figure 5. (a) Distribution of percentage difference (method for calculating percentage differences: $\left.\left\{\left(\frac{\mathrm{L} 3 \mathrm{~W}}{\mathrm{~L} 3 \mathrm{~L}}\right) \cdot 100\right\}-100\right)$ between simulated temporally coincident VMR retrievals in $\mathrm{L} 3 \mathrm{~W}\left(\mathrm{SIM}_{\mathrm{L} 3 \mathrm{~W}}\right)$ and $\mathrm{L} 3 \mathrm{~L}\left(\mathrm{SIM}_{\mathrm{L} 3 \mathrm{~L}}\right)$. Squares represent mean differences. The $p$ value associated with each mean difference (from a two-tailed Student $t$ test) is given on the right-hand-side $y$ axis (top value shows $\Delta$ SIM; bottom value shows $\triangle$ RET). Plus symbols represent outliers (outliers defined as above (below) percentile $75(25)+(-) 1.5 \cdot$ interquartile range). Faint shading shows the corresponding $\triangle$ RET boxplots for comparison. Note that the sample size is different to Fig. 2 owing to the CAMSRA data used as the $\boldsymbol{X}_{\mathrm{tr}, \text { sim }}$ profile only covering a subset of the MOPITT years (2003-2016 vs. 2001-2017 in Fig. 2). The $\Delta$ RET boxplots overlaid

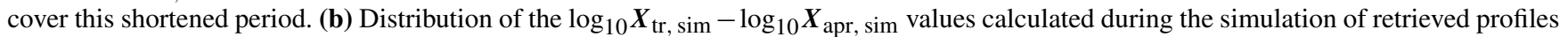
(see Eq. 2) in DJF (top subpanel) and JJA (bottom subpanel). 
closer $\boldsymbol{X}_{\mathrm{tr}, \text { sim }}$ and $\boldsymbol{X}_{\mathrm{apr}, \text { sim }}$ profiles combine with small sensitivity differences to limit $\Delta$ SIM in DJF. A final, alternative explanation for $\triangle$ SIM being a poor match for $\triangle$ RET in DJF, unlike in JJA, is that sensitivity differences in L3L and L3W could have less of an impact on $\triangle$ RET in DJF than in JJA and that something else is responsible - for example, real differences between the true $\mathrm{CO}$ profile over land and water. This is something we explore in detail in the following sections.

\subsubsection{Regional land-water contrast in L2 data}

To further evaluate whether $\triangle$ RET within the L3 grid box containing Halifax is a function of land-water sensitivity contrasts or actually due to real gradients in the true CO profile (for example, due to offshore transport of emissions from the city of Halifax or marine-land chemistry differences), we analyse the characteristics of retrieved profiles over the broader geographical region surrounding Halifax. If $\triangle$ RET is linked to sensitivity, then we would expect there to be a clear land-sea contrast across the whole region. This is exactly what we see. Figure 6 shows seasonal median $\mathrm{L} 2$ retrieved and a priori $\mathrm{CO}$ concentrations for the surface level of the profile, where $\triangle \mathrm{RET}$ and $\mathrm{L} 3 \mathrm{~L}-\mathrm{L} 3 \mathrm{~W}$ AK differences are greatest and most significant, for the Canadian maritime provinces and a small portion of the northeastern United States (note that we show seasonal median fields here as the spatial patterns are clearer than for plots consisting only of the subset of days analysed in the rest of this section. The corresponding plot for the subset of days is shown in Sect. S3, and the main findings are unchanged). Difference fields (RET-APR) are also shown. In JJA, a land-sea contrast is remarkably clear in both the retrieved and RET-APR fields. The a priori field shows elevated $\mathrm{CO}$ amounts emanating from the west-southwest (indicative of $\mathrm{CO}$ sources in the northeastern United States and around the Great Lakes) and decreasing quite smoothly towards the north and east. The west-southwest maxima is replicated in the retrieved field, but the smoothly decreasing gradient is clearly broken, with the land in the image characterized by lower $\mathrm{CO}$ values than the adjacent ocean. This contrast is enhanced further in the RET-APR field. RET-APR values close to zero indicate either very low retrieval sensitivity or closely matching retrieved and a priori values. The analysis of averaging kernels in Sect. 3.1.2 demonstrated the lack of retrieval sensitivity at the surface over water (in L3W) in JJA. On average, the RET-APR field is 11.5 ppbv lower over land than over water (determined by binning the $\mathrm{L} 2$ data for the region shown according to surface classification). This reinforces our earlier interpretation that, in JJA, LT retrievals in L3W are weighted more heavily towards an a priori profile in which $\mathrm{CO}$ concentrations are too high than LT retrievals in L3L.

The land-sea contrast is less clear in DJF, although the RET-APR field does indicate generally positive values over water and negative values over land. The contrast being less apparent in DJF compared to JJA is consistent with the smaller L3L-L3W AK differences in DJF compared to JJA. However, it is surprising that RET-APR changes sign from land (generally negative) to water (generally positive). This may be linked to some factor other than retrieval sensitivity to the true $\mathrm{CO}$ profile, such as errors in retrieved/a priori surface temperatures or emissivities, which are important components of the radiative transfer model used in MOPITT's $\mathrm{CO}$ retrieval algorithm. If this were the case over the sea, it could explain the maxima in RET-APR values to the northwest of Halifax in the Bay of Fundy, where the water is relatively shallow and the tidal range is the highest in the world at $16.3 \mathrm{~m}$, transporting large amounts of suspended sediments (which will affect emissivity). Alternatively, the difference could reflect a physical process causing elevated $\mathrm{CO}$ over the ocean, although this seems unlikely, as we expect atmospheric transport to minimize such a contrast.

Corresponding maps for other selected levels of the profile and TCO are shown in Sect. S4. In JJA, a land-sea contrast is qualitatively evident at all levels and for TCO, with the exception of $800 \mathrm{hPa}$; and in DJF a contrast is evident at $800 \mathrm{hPa}$ and for TCO.

\subsubsection{Can $\triangle$ RET be explained by circulation-driven horizontal gradients in the true $\mathrm{CO}$ profile?}

The preceding sections presented evidence that differences in temporally coincident $\mathrm{L} 3 \mathrm{~L}$ and $\mathrm{L} 3 \mathrm{~W}$ retrieved profiles are linked to sensitivity contrasts over land and water, especially in JJA and in the LT. However, these differences could also be a result of horizontal gradients in the true $\mathrm{CO}$ profile. It is plausible that retrieved LT VMRs are greater in L3W than in L3L due to for example offshore transportation of $\mathrm{CO}$ by regional winds either from Halifax or from the large polluting areas on the northeast coast of the US and around the Great Lakes (as seen in the general decline in $\mathrm{CO}$ amounts from the west-southwest towards the northeast in Fig. 6). Winds generally tend from the west, northwest or southwest in this area (Fig. 7), which will lead to offshore transport of continental pollution.

We compare composite mean wind patterns across Nova Scotia using ERA-Interim data for days when retrieved surface level VMRs in $\mathrm{L} 3 \mathrm{~W}$ are greater than in $\mathrm{L} 3 \mathrm{~L}(\mathrm{~L} 3 \mathrm{~W}>$ $\mathrm{L} 3 \mathrm{~L})$ and days when they are less $(\mathrm{L} 3 \mathrm{~W}<\mathrm{L} 3 \mathrm{~L})$, since a clear shift in wind direction on these days would support the case that atmospheric transport plays a role in generating differences in retrieved $\mathrm{CO}$ amounts over land and water. These are shown in Fig. 7 (10 m winds are used). There is a clear circulation difference evident in DJF. When L3W $>$ L3L (12 d of the 18 in Fig. 2) the wind is in an offshore direction, whereas when $\mathrm{L} 3 \mathrm{~W}<\mathrm{L} 3 \mathrm{~L}$ ( $6 \mathrm{~d}$ of the 18 in Fig. 2) the wind is alongshore from the west-southwest (and noticeably weaker). This is evidence to suggest that the LT $\triangle$ RET patterns in DJF are linked to the horizontal gradients in the true $\mathrm{CO}$ profile, although the small sample sizes involved here dictate caution. In contrast to DJF, however, 

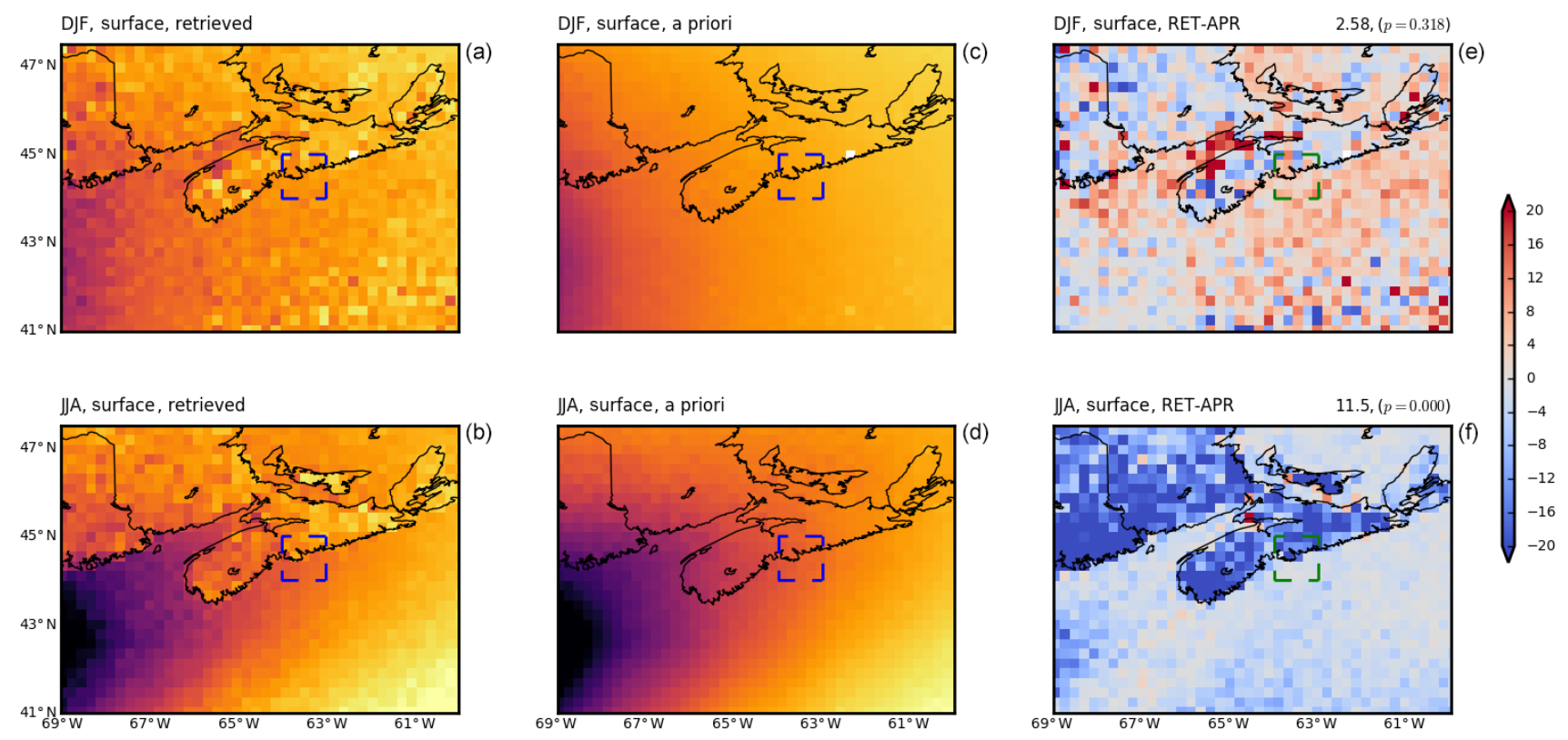

ํㅛㄹ

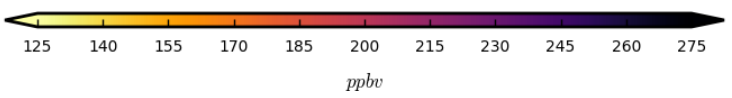

Figure 6. Seasonal median L2 (these maps were created from L2 data that were interpolated to a regular $0.25^{\circ} \times 0.25^{\circ}$ grid for ease of plotting.) retrieved VMR (a, b), a priori VMR (c, d), and RET-APR (e, f) at the surface profile level in DJF (a, c, e) and JJA (b, d, f).

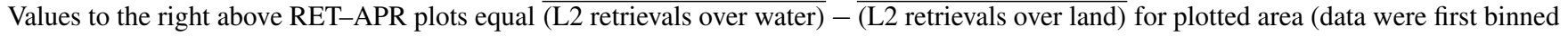
according to L2 surface index); numbers in brackets correspond to significance of mean difference using a two-tailed Student $t$ test. Blue or green dashed squares represent the outline of the L3 grid box that contains Halifax.

there is no clear circulation difference in JJA; the winds are generally from the west-southwest irrespective of whether $\mathrm{L} 3 \mathrm{~W}>\mathrm{L} 3 \mathrm{~L}$ or $\mathrm{L} 3 \mathrm{~W}<\mathrm{L} 3 \mathrm{~L}$. This lends further support to the conclusion that LT $\triangle$ RET in JJA is strongly linked to the demonstrated land-water sensitivity contrast. The seasonal difference in these results could explain why LT (and especially near-surface) $\triangle$ RET is of comparable magnitudes in DJF and JJA (Sect. 3.1.1), despite smaller L3L-L3W retrieval sensitivity contrasts and $\triangle$ SIM values in DJF than JJA (Sect. 3.1.2 and 3.1.3 respectively). In other words, in DJF, $\triangle \mathrm{RET}$ is more indicative of differences in true $\mathrm{CO}$ concentrations, while in JJA it is more strongly tied to differences in retrieval sensitivity. This is not to say contrasts in retrieval sensitivity do not influence LT $\triangle$ RET in DJF - just that the effect is not as strong as in JJA, when the LT sensitivity contrast is greater. We only consider the surface profile level here; the findings are consistent higher up in the LT, but the DJF circulation difference is absent in the MT (see Sect. S5), consistent with $\triangle$ RET being much smaller in the MT and above, on average.

While there is no obvious circulation difference at the surface in JJA between days when $\mathrm{L} 3 \mathrm{~W}>\mathrm{L} 3 \mathrm{~L}$ and $\mathrm{L} 3 \mathrm{~W}<$ $\mathrm{L} 3 \mathrm{~L}$, there is a difference in the distribution of these days throughout the analysed MOPITT time series, which spans 16 JJA seasons from 2001 to 2016. A total of 16 of the
$19 \mathrm{~d}$ when $\mathrm{L} 3 \mathrm{~W}<\mathrm{L} 3 \mathrm{~L}$ occur in the first half of the time series (i.e. before 2009), whereas days when $\mathrm{L} 3 \mathrm{~W}>\mathrm{L} 3 \mathrm{~L}$ are spread more evenly throughout (33 of the $65 \mathrm{~d}(51 \%)$ occur before 2009). In DJF there is no such difference, with roughly $50 \%$ of days occurring before and after 2009 in each case. This is something we explore further in Sect. 3.2.2.

\subsection{Consequences for $\mathrm{L3O}$ time series}

In this section we demonstrate how the statistics of the $\mathrm{L} 3 \mathrm{O}$ time series, and the results of a typical trend analysis using those data, are affected by the loss of LT retrieval information from L2 products over land when the L3 products for the coastal grid box containing Halifax are created. We do this through comparison with the $\mathrm{L} 3 \mathrm{~L}$ and $\mathrm{L} 3 \mathrm{~W}$ time series. Because users of L3 data are advised to filter according to surface index in order to limit their analysis to retrievals with maximal information content, we consider $\mathrm{L} 3 \mathrm{O}$ subsets that remain after filtering the time series for days with a surface index of water and mixed ( $\mathrm{L} \mathrm{O}_{\text {(water) }}$ and $\mathrm{L} 3 \mathrm{O}_{\text {(mixed) }}$ ), as well as the unfiltered $\mathrm{L} 3 \mathrm{O}$ time series to evaluate the full range of options available to users of the products. $\mathrm{L} 3 \mathrm{O}$ only has a surface index of land once each season, so this subset is omitted. We focus on the LT profile levels since this is where retrieval sensitivity differences are greatest and can be 

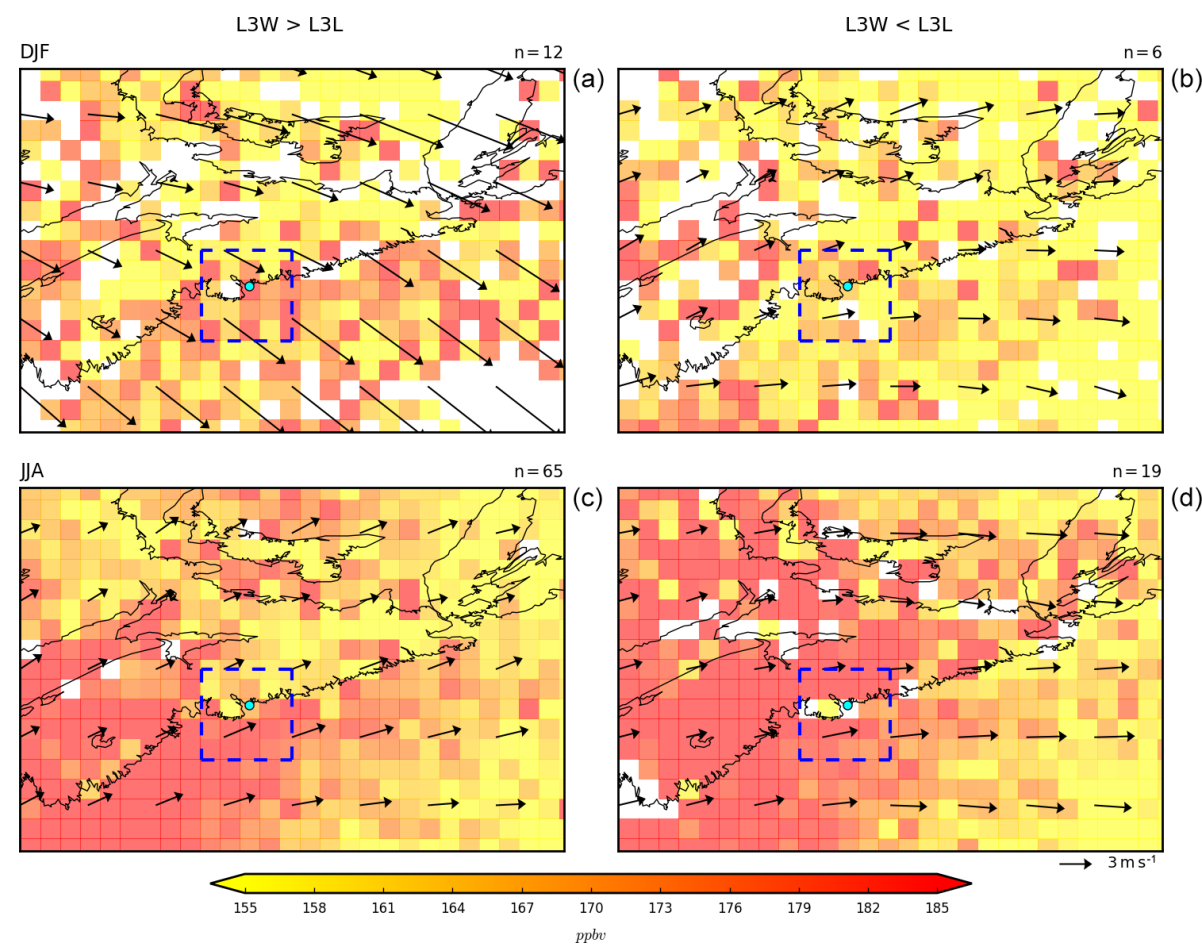

Figure 7. Mean ERA-Interim $10 \mathrm{~m}$ winds (vectors) and MOPITT L2 (these maps were created from L2 data that were interpolated to a regular $0.25^{\circ} \times 0.25^{\circ}$ grid for ease of plotting) VMR at the surface profile level (shading) for days when retrieved surface level VMRs in $\mathrm{L} 3 \mathrm{~W}$ are greater than in L3L (L3W > L3L) and days when they are less (L3W < L3L). (a, b) DJF; (c, d) JJA. Blue dashed square represents the outline of the $\mathrm{L} 3$ grid box that contains Halifax.

linked to differences in retrieved $\mathrm{CO}$ values, as shown in the previous analyses.

\subsubsection{Impact on seasonal data distribution}

Seasonal surface level VMR distributions for L3L, L3W and all L3O subsets are shown in Fig. 8. Most strikingly, L3L is the clear outlier in JJA. Mean VMRs are significantly lower than in all other time series ( $p<0.1$ in all cases), and the spread of values is around twice as large, both in terms of the interquartile range and overall range (excluding outliers), with this difference mostly coming from the lower end of the distribution. This is unsurprising when comparing L3L with the time series that are based purely on retrievals over water ( $\mathrm{L} 3 \mathrm{~W}$ and $\mathrm{L}^{3} \mathrm{O}_{\text {(water) }}$ ), given the demonstration in previous sections that retrievals over water have significantly lower information content than over land in the summer months and are therefore more closely tied to the a priori $\mathrm{CO}$ concentration (i.e. retrieved VMRs will vary less). However, it clearly shows how the valuable additional information on true $\mathrm{CO}$ content that is available in L2 retrievals over land is diluted by their averaging with retrievals over water for $\mathrm{L}^{3} \mathrm{O}_{\text {(mixed) }}$ days (mean surface level $\mathrm{AK}$ rowsum is 0.38 for $\mathrm{L} 3 \mathrm{O}_{\text {(mixed) }}$ vs. 0.69 for L3L and 0.14 for L3W; see Fig. 3), effectively creating a high bias in the resulting gridded mean VMRs. The loss of retrieval information from L2 to L3 is actually exacerbated for this $1^{\circ} \times 1^{\circ} \mathrm{L} 3$ coastal grid box containing Halifax, given that a greater number of L2 retrievals over water contribute to the gridded averages than L2 retrievals over land (as previously outlined in Table 1), primarily because more of the surface within the L3 grid box is water than land (see Fig. 1). Consequently, the $\mathrm{L}^{3} \mathrm{O}_{\text {(mixed) }}$ distribution more closely resembles L3W than L3L (although the $\mathrm{L} 3 \mathrm{~W}-\mathrm{L} 3 \mathrm{O}_{\text {(mixed) }}$ mean difference is still statistically significant, $p<0.1$ ). Owing to the lack of days when the $\mathrm{L} 3 \mathrm{O}$ time series is created only from retrievals over land, $\mathrm{L} \mathrm{O}_{\text {(mixed) }}$ represents the best option for quantifying surface level $\mathrm{CO}$ in $\mathrm{JJA}$ that is available to users of the original $\mathrm{L} 3$ product in this case. The optimal retrievals for this task are only available in the L2 data products, a direct result of the way that the L3 products are created.

For the same reasons discussed above, $\mathrm{L} 3 \mathrm{~L}$ also represents the outlier distribution in DJF. Unlike in JJA however, the spread of VMR values is similar in L3L and L3W, likely reflecting the fact that there is some surface level sensitivity in retrievals over both land and water in DJF, allowing for a similar degree of departure from the a priori. The main difference in the distributions is that VMRs in L3L are offset towards lower values. However, the mean difference is not significant between L3L and any of the other time series. Also unlike in JJA, L3L does not necessarily represent the optimal time series for analysing surface level CO in DJF, since 

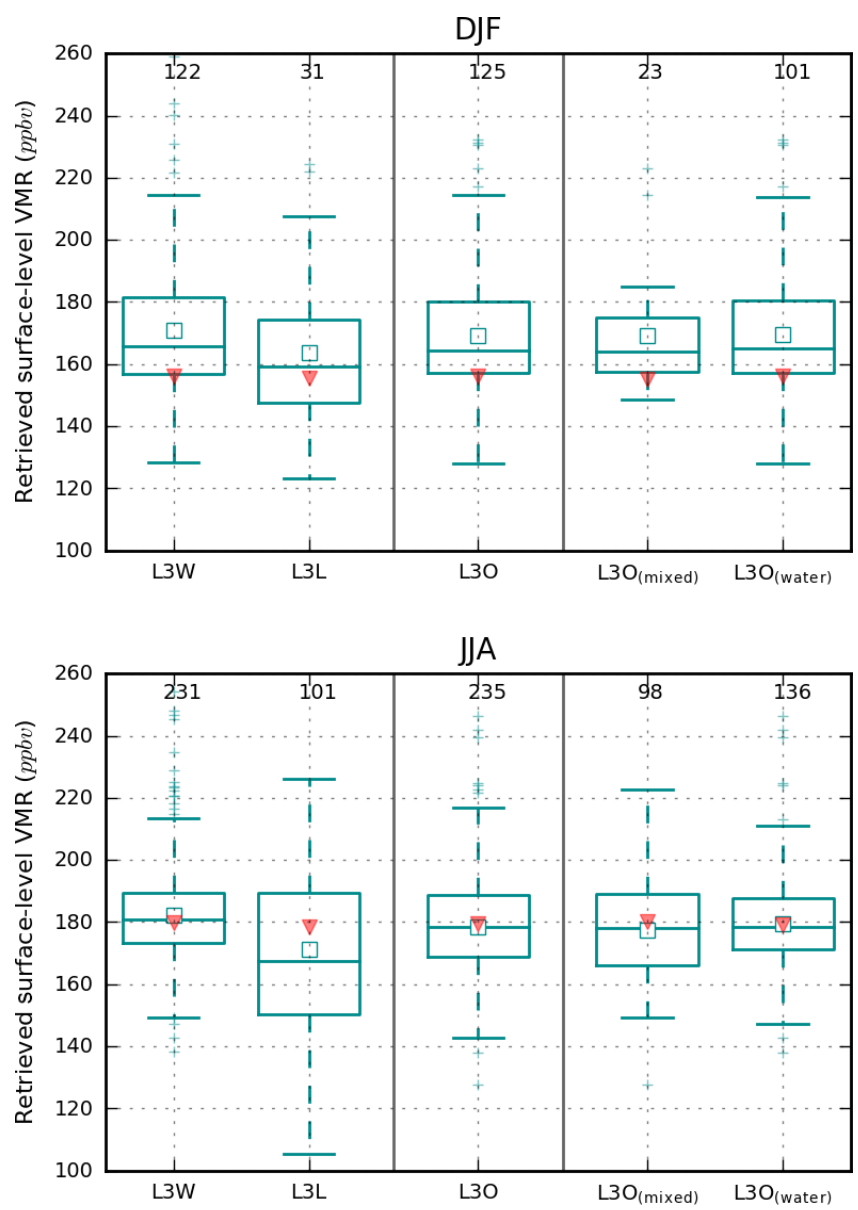

Figure 8. Boxplots showing the seasonal distribution of retrieved surface level VMR values from $\mathrm{L} 3 \mathrm{~W}, \mathrm{~L} 3 \mathrm{~L}, \mathrm{~L} 3 \mathrm{O}, \mathrm{L}^{3} \mathrm{O}_{\text {(mixed) }}$ and

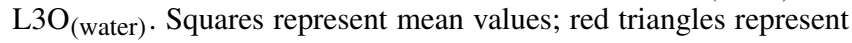
corresponding mean a priori values. Sample sizes are given below the top $x$ axis.

retrieval sensitivity is actually higher over water in this season. Information loss resulting from the way L3 products are created is therefore less of an issue than in JJA, owing to the dominance of retrievals over water on the $\mathrm{L} 3 \mathrm{O}$ time series (mean surface level AK rowsum is 0.52 for $\mathrm{L}_{3} \mathrm{O}_{\text {(mixed) }}$ vs. 0.43 for L3L and 0.53 for L3W; see Fig. 3). It is worth noting, however, that $\mathrm{L} 3 \mathrm{~W}$ offers $\sim 25 \%$ more days with data than $\mathrm{L}^{3} \mathrm{O}_{\text {(water) }}$ in DJF, due to the fact that it gains the retrievals over water that go into $\mathrm{L}^{3} \mathrm{O}_{\text {(mixed) }}$. This is potentially valuable additional temporal information for users of MOPITT products.

Although the sample sizes considered here are different, because L 2 retrievals over land and water are not necessarily always present on the same days (e.g. due to variable cloud coverage), the differences in seasonal data distribution discussed in this section hold if the analysis is restricted to only days when L3L and L3W are both present (see Sect. S6). We have only presented analysis for the surface level of the pro- file here as this is where $\mathrm{L} 3 \mathrm{~L}-\mathrm{L} 3 \mathrm{~W}$ differences in retrieved VMRs and retrieval sensitivity are greatest. Plots of other levels are given in Sect. S7.

\subsubsection{Consequences for temporal trend analysis}

To identify and compare temporal trends in the time series considered above, we perform weighted least squares (WLS) regression analyses on respective seasonal mean profile and TCO values, weighted by the standard deviation of the measurements used in the seasonal mean. For seasons that contain just a single measurement, we use the data record standard deviation scaled by a factor of 100 so as to de-weight these seasons in the fit. All trends identified are detailed in Table 3, and WLS best-fit lines, along with boxplots of seasonal data distributions, are presented for the surface level in Fig. 9. Here, the decreasing trend identified in $\mathrm{L} 3 \mathrm{~L}$ is over four times stronger than the trend in $\mathrm{L} 3 \mathrm{~W}$, a highly significant difference $(p<0.01)$. This is a direct consequence of surface level retrievals over water being tied closely to the a priori owing to their negligible sensitivity, which has no yearly change. This effectively masks the full magnitude of the decrease in $\mathrm{CO}$ that appears to be occurring, and which is better detected by retrievals over land owing to their greater sensitivity. Consequently, trends in all L3O subsets are also significantly weaker than the trend in L3L. Since it has some contribution from retrievals over land, $\mathrm{L}^{3} \mathrm{O}_{\text {(mixed) }}$ provides the closest approximation of the trend in L3L, but it is still over $50 \%$ weaker - representing a decrease of $10 \%$ (19 ppbv) over the 15 -year period covered by the analysis vs. $21 \%$ (40 ppbv) in L3L. Compared to JJA, trends in surface level VMRs in DJF are far more similar across all the time series, with no significant differences between any of the trends identified. This is attributable to the much smaller differences in retrieval sensitivity over land and water in this season. Thus, while the greater number of days corresponding to the L3W time series makes it of potentially greater value than

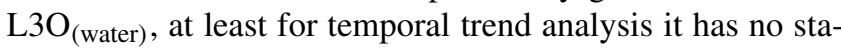
tistical benefit (in fact, users of the original L3 product would seem to get comparable results by performing the analysis on the unfiltered version of $\mathrm{L3O}$ ).

Although the land-water retrieval sensitivity contrast remains large at the $900 \mathrm{hPa}$ level in JJA, the trend in $\mathrm{L} 3 \mathrm{O}_{\text {(mixed) }}$ is a closer match to $\mathrm{L} 3 \mathrm{~L}$ than at the surface, and the difference loses statistical significance. The loss of information content available in retrievals at the $900 \mathrm{hPa}$ level over land during the creation of $\mathrm{L} 3 \mathrm{O}$ (mean $900 \mathrm{hPa} \mathrm{AK}$ rowsum is 0.91 for $\mathrm{L} 3 \mathrm{~L}$ vs. 0.64 for $\mathrm{L}^{3} \mathrm{O}_{\text {(mixed) }}$ ) therefore does not have a statistically significant impact on temporal trends identified using $\mathrm{L}^{3} \mathrm{O}_{\text {(mixed) }}$, when compared to $\mathrm{L} 3 \mathrm{~L}$. Although the L3L-L3W trend difference is smaller than at the surface level, L3L is still twice as strong as L3W and the difference remains statistically significant. This could be a result of either the retrieval over water still lacking sufficient information to deviate as far from the a priori as the retrieval 
Table 3. Results from WLS regression analysis of seasonal mean $\mathrm{L} 3 \mathrm{~W}, \mathrm{~L} 3 \mathrm{~L}, \mathrm{~L} 3 \mathrm{O}, \mathrm{L} 3 \mathrm{O}_{(\text {water) }}$ and $\mathrm{L} 3 \mathrm{O}_{(\text {mixed) }}$ time series for selected profile levels in DJF and JJA. Trend corresponds to the gradient of the WLS best-fit line; SE is the standard error of the trend; $P$ value is the probability that the trend is zero; \% change per year is the mean percentage change in retrieved CO per year, calculated from WLS regression model predicted values as follows: \%change per year $=\left\{\left[\left(\right.\right.\right.$ Predicted $\left.\left.\left._{\text {last }}\right) \cdot 100\right]-100\right\} /$ ny , where ny is the number of years The penultimate two columns correspond to the result of a significance test performed on the difference between that row's trend and the trend in $\mathrm{L} 3 \mathrm{~L}$ and $\mathrm{L} 3 \mathrm{~W}$, respectively, as follows: $Z=\frac{\mathrm{Trend}_{1}-\mathrm{Trend}_{2}}{\sqrt{\mathrm{SE}_{1}^{2}+\mathrm{SE}_{2}^{2}}}$, where $\mathrm{SE}_{1}$ and $\mathrm{SE}_{2}$ correspond to the standard errors of Trend 1 and Trend $_{2}$ respectively, and $Z$ is the test statistic. Where $Z$ is greater (less) than $1.645(-1.645)$, the trend difference is statistically significant to at least $90 \%$ (i.e. $p<0.1$ ). Drift is the measurement drift values given in Deeter et al. (2017). No values are given for the 900 and $300 \mathrm{hPa}$ levels of the profile: we therefore cite values for the 400 and $200 \mathrm{hPa}$ levels to give context to the $300 \mathrm{hPa}$ trends we show; and we expect that the $900 \mathrm{hPa}$ level drift is somewhere between that of the surface and $800 \mathrm{hPa}$ levels, which are both shown.

\begin{tabular}{|c|c|c|c|c|c|c|c|c|c|}
\hline & \multirow[t]{2}{*}{ Level } & \multirow[t]{2}{*}{ Time series } & \multirow[t]{2}{*}{ Trend (ppbv)* } & \multirow[t]{2}{*}{ SE (ppbv)* } & \multirow[t]{2}{*}{$P$ value } & \multirow[t]{2}{*}{$\%$ change per year } & \multicolumn{2}{|c|}{ Sig. diff. to } & \multirow[t]{2}{*}{$\operatorname{Drift}\left(\% \mathrm{yr}^{-1}\right)$} \\
\hline & & & & & & & L3L & L3W & \\
\hline \multicolumn{10}{|l|}{ DJF } \\
\hline $\mathrm{nL} 3 \mathrm{~W}=122$ & Surface & L3W & -1.63 & 0.33 & 0.000 & -0.84 & No & $\mathrm{n} / \mathrm{a}$ & \\
\hline $\mathrm{nL} 3 \mathrm{~L}=31$ & & L3L & -2.11 & 0.6 & 0.006 & -1.13 & $\mathrm{n} / \mathrm{a}$ & No & \\
\hline $\mathrm{nL} 3 \mathrm{O}=125$ & & $\mathrm{~L} 3 \mathrm{O}$ & -1.74 & 0.31 & 0.000 & -0.90 & No & No & $-0.69 \pm 0.10$ \\
\hline $\mathrm{nL} 3 \mathrm{O}_{(\text {water })}=101$ & & $\mathrm{~L}^{3} \mathrm{O}_{\text {(water) }}$ & -1.92 & 0.33 & 0.000 & -0.32 & No & No & \\
\hline \multirow[t]{26}{*}{$\mathrm{nL} 3 \mathrm{O}_{(\text {mixed })}=23$} & & $\mathrm{~L} 3 \mathrm{O}_{\text {(mixed) }}$ & -1.29 & 0.28 & 0.001 & -0.68 & No & No & \\
\hline & $900 \mathrm{hPa}$ & L3W & -2.39 & 0.29 & 0.000 & -1.26 & No & $\mathrm{n} / \mathrm{a}$ & \\
\hline & & L3L & -3.14 & 0.48 & 0.000 & -1.72 & $\mathrm{n} / \mathrm{a}$ & No & \\
\hline & & $\mathrm{L} 3 \mathrm{O}$ & -2.51 & 0.29 & 0.000 & -1.32 & No & No & Not given \\
\hline & & $\mathrm{L}^{3} \mathrm{O}_{\text {(water) }}$ & -2.4 & 0.25 & 0.000 & -1.26 & No & No & \\
\hline & & $\mathrm{L}^{3} \mathrm{O}_{\text {(mixed) }}$ & -3.05 & 0.35 & 0.000 & -1.61 & No & No & \\
\hline & $800 \mathrm{hPa}$ & L3W & -2.36 & 0.3 & 0.000 & -1.41 & No & $\mathrm{n} / \mathrm{a}$ & \\
\hline & & L3L & -2.9 & 0.35 & 0.000 & -1.79 & $\mathrm{n} / \mathrm{a}$ & No & \\
\hline & & L3O & -2.47 & 0.29 & 0.000 & -1.48 & No & No & $-1.04 \pm 0.11$ \\
\hline & & $\mathrm{L}^{3} \mathrm{O}_{\text {(water) }}$ & -2.49 & 0.27 & 0.000 & -1.47 & No & No & \\
\hline & & $\mathrm{L} 3 \mathrm{O}_{\text {(mixed) }}$ & -3.56 & 0.42 & 0.000 & -2.08 & No & Yes & \\
\hline & $600 \mathrm{hPa}$ & L3W & -0.962 & 0.39 & 0.027 & -0.75 & No & $\mathrm{n} / \mathrm{a}$ & \\
\hline & & L3L & -2.1 & 0.63 & 0.007 & -1.58 & $\mathrm{n} / \mathrm{a}$ & No & \\
\hline & & $\mathrm{L} 3 \mathrm{O}$ & -1.21 & 0.41 & 0.011 & -0.93 & No & No & $-0.33 \pm 0.09$ \\
\hline & & $\mathrm{L}^{3} \mathrm{O}_{\text {(water) }}$ & -1.04 & 0.41 & 0.025 & -0.80 & No & No & \\
\hline & & $\mathrm{L} 3 \mathrm{O}_{\text {(mixed) }}$ & -1.48 & 0.43 & 0.007 & -1.18 & No & No & \\
\hline & $300 \mathrm{hPa}$ & L3W & 0.704 & 0.3 & 0.034 & 0.87 & Yes & $\mathrm{n} / \mathrm{a}$ & $400 \mathrm{hPa}:$ \\
\hline & & L3L & -0.507 & 0.65 & 0.456 & -0.56 & $\mathrm{n} / \mathrm{a}$ & Yes & $1.15 \pm 0.12$ \\
\hline & & $\mathrm{L} 3 \mathrm{O}$ & 0.58 & 0.35 & 0.122 & 0.71 & No & No & $200 \mathrm{hPa}:$ \\
\hline & & $\mathrm{L} 3 \mathrm{O}_{\text {(water) }}$ & 0.49 & 0.20 & 0.030 & 0.59 & No & No & $1.49 \pm 0.13$ \\
\hline & & L3O $\mathrm{O}_{\text {(mixed) }}$ & 0.483 & 0.65 & 0.475 & 0.59 & No & No & \\
\hline & TCO & L3W & $-2.16 \times 10^{16}$ & $4.70 \times 10^{15}$ & 0.000 & -0.81 & No & $\mathrm{n} / \mathrm{a}$ & \\
\hline & & L3L & $-2.27 \times 10^{16}$ & $6.00 \times 10^{15}$ & 0.000 & -0.89 & $\mathrm{n} / \mathrm{a}$ & No & \\
\hline & & $\mathrm{L} 3 \mathrm{O}$ & $-2.56 \times 10^{16}$ & $4.70 \times 10^{15}$ & 0.000 & -0.95 & No & No & $0.001 \pm 0.001$ \\
\hline & & $\mathrm{L}^{3} \mathrm{O}_{\text {(water) }}$ & $-2.08 \times 10^{16}$ & $5.10 \times 10^{15}$ & 0.001 & -0.79 & No & No & \\
\hline & & $\mathrm{L} 3 \mathrm{O}_{\text {(mixed) }}$ & $-3.24 \times 10^{16}$ & $3.50 \times 10^{15}$ & 0.000 & -1.19 & No & Yes & \\
\hline
\end{tabular}

over land, despite the increase in information content relative to the surface level (mean AK rowsums is 0.15 and 0.44 for the surface and $900 \mathrm{hPa}$ levels respectively); and/or the retrieval at the $900 \mathrm{hPa}$ level over water having a sensitivity peak higher up in the troposphere where $\mathrm{CO}$ concentrations may be decreasing at a slower rate than they are closer to the surface, where sensitivity peaks for the $900 \mathrm{hPa}$ level over land (see Fig. 3). By $800 \mathrm{hPa}$, trends in all time series in JJA have converged, consistent with the further weakening of the land-water sensitivity contrast.
Moving away from the LT, the trends outlined in Table 3 indicate that all time series generally agree on the broad picture: in both seasons, CO concentrations are decreasing in the LT and MT and increasing in the UT, while TCO shows a decrease in DJF and no significant trend in JJA. Although not as pronounced or significant as at the surface in JJA, in all cases there are differences in the magnitude of the identified trend. This is not unexpected given that the seasonal means being regressed differ between time series. As outlined in Sect. 3.1.1 and 3.1.2, temporally coincident retrieved VMRs 
Table 3. Continued.

\begin{tabular}{|c|c|c|c|c|c|c|c|c|c|}
\hline & \multirow[t]{2}{*}{ Level } & \multirow[t]{2}{*}{ Time series } & \multirow[t]{2}{*}{ Trend (ppbv)* } & \multirow[t]{2}{*}{ SE (ppbv)* } & \multirow[t]{2}{*}{$P$ value } & \multirow[t]{2}{*}{$\%$ change per year } & \multicolumn{2}{|c|}{ Sig. diff. to } & \multirow[t]{2}{*}{$\operatorname{Drift}\left(\% \mathrm{yr}^{-1}\right)$} \\
\hline & & & & & & & L3L & L3W & \\
\hline \multicolumn{10}{|l|}{ JJA } \\
\hline $\mathrm{nL} 3 \mathrm{~W}=231$ & Surface & L3W & -0.69 & 0.33 & 0.058 & -0.35 & Yes & $\mathrm{n} / \mathrm{a}$ & \\
\hline $\mathrm{nL} 3 \mathrm{~L}=101$ & & L3L & -2.85 & 0.60 & 0.000 & -1.42 & $\mathrm{n} / \mathrm{a}$ & Yes & \\
\hline $\mathrm{nL} 3 \mathrm{O}=235$ & & $\mathrm{~L} 3 \mathrm{O}$ & -0.99 & 0.28 & 0.003 & -0.50 & Yes & No & $-0.69 \pm 0.10$ \\
\hline $\mathrm{nL} 3 \mathrm{O}_{(\text {water })}=136$ & & $\mathrm{~L}^{3} \mathrm{O}_{\text {(water) }}$ & -0.62 & 0.31 & 0.069 & -0.32 & Yes & No & \\
\hline \multirow[t]{26}{*}{$\mathrm{nL} 3 \mathrm{O}_{\text {(mixed) }}=98$} & & $\mathrm{~L} 3 \mathrm{O}_{\text {(mixed) }}$ & -1.35 & 0.35 & 0.002 & -0.68 & Yes & No & \\
\hline & $900 \mathrm{hPa}$ & L3W & -1.34 & 0.31 & 0.001 & -0.81 & Yes & $\mathrm{n} / \mathrm{a}$ & \\
\hline & & L3L & -2.58 & 0.60 & 0.001 & -1.55 & $\mathrm{n} / \mathrm{a}$ & Yes & \\
\hline & & $\mathrm{L} 3 \mathrm{O}$ & -1.43 & 0.35 & 0.001 & -0.87 & Yes & No & Not given \\
\hline & & $\mathrm{L}^{3} \mathrm{O}_{\text {(water) }}$ & -0.91 & 0.38 & 0.032 & -0.56 & Yes & No & \\
\hline & & $\mathrm{L} 3 \mathrm{O}_{\text {(mixed) }}$ & -2.05 & 0.45 & 0.001 & -1.23 & No & No & \\
\hline & $800 \mathrm{hPa}$ & L3W & -1.55 & 0.41 & 0.002 & -1.10 & No & $\mathrm{n} / \mathrm{a}$ & \\
\hline & & $\mathrm{L} 3 \mathrm{~L}$ & -1.62 & 0.54 & 0.010 & -1.22 & $\mathrm{n} / \mathrm{a}$ & No & \\
\hline & & $\mathrm{L} 3 \mathrm{O}$ & -1.47 & 0.39 & 0.002 & -1.07 & No & No & $-1.04 \pm 0.11$ \\
\hline & & $\mathrm{L} 3 \mathrm{O}_{\text {(water) }}$ & -1.01 & 0.46 & 0.049 & -0.75 & No & No & \\
\hline & & $\mathrm{L} \mathrm{O}_{\text {(mixed) }}$ & -1.89 & 0.48 & 0.002 & -1.38 & No & No & \\
\hline & $600 \mathrm{hPa}$ & L3W & -0.91 & 0.46 & 0.071 & -0.83 & No & $\mathrm{n} / \mathrm{a}$ & \\
\hline & & L3L & -0.38 & 0.47 & 0.440 & -0.36 & $\mathrm{n} / \mathrm{a}$ & No & \\
\hline & & $\mathrm{L} 3 \mathrm{O}$ & -0.75 & 0.43 & 0.105 & -0.70 & No & No & $-0.33 \pm 0.09$ \\
\hline & & $\mathrm{L}^{3} \mathrm{O}_{\text {(water) }}$ & -0.41 & 0.49 & 0.424 & -0.39 & No & No & \\
\hline & & $\mathrm{L} 3 \mathrm{O}_{\text {(mixed) }}$ & -1.12 & 0.45 & 0.026 & -1.02 & No & No & \\
\hline & $300 \mathrm{hPa}$ & L3W & 1.30 & 0.43 & 0.010 & 1.40 & No & $\mathrm{n} / \mathrm{a}$ & $400 \mathrm{hPa}:$ \\
\hline & & $\mathrm{L} 3 \mathrm{~L}$ & 2.51 & 1.30 & 0.072 & 2.90 & $\mathrm{n} / \mathrm{a}$ & No & $1.15 \pm 0.12$ \\
\hline & & $\mathrm{L} 3 \mathrm{O}$ & 1.38 & 0.47 & 0.011 & 1.52 & No & No & $200 \mathrm{hPa}:$ \\
\hline & & $\mathrm{L}^{3} \mathrm{O}_{\text {(water) }}$ & 0.86 & 0.42 & 0.060 & 0.92 & No & No & $1.49 \pm 0.13$ \\
\hline & & $\mathrm{L} 3 \mathrm{O}_{\text {(mixed) }}$ & 2.24 & 0.53 & 0.001 & 2.52 & No & No & \\
\hline & TCO & L3W & $-9.84 \times 10^{15}$ & $5.70 \times 10^{15}$ & 0.109 & -0.40 & No & $\mathrm{n} / \mathrm{a}$ & \\
\hline & & $\mathrm{L} 3 \mathrm{~L}$ & $-1.01 \times 10^{16}$ & $1.00 \times 10^{16}$ & 0.331 & -0.42 & $\mathrm{n} / \mathrm{a}$ & No & \\
\hline & & $\mathrm{L} 3 \mathrm{O}$ & $-8.75 \times 10^{15}$ & $6.40 \times 10^{15}$ & 0.192 & -0.36 & No & No & $0.001 \pm 0.001$ \\
\hline & & $\mathrm{L}^{3 \mathrm{O}_{\text {(water) }}}$ & $-7.62 \times 10^{15}$ & $6.80 \times 10^{15}$ & 0.282 & -0.32 & No & No & \\
\hline & & $\mathrm{L} 3 \mathrm{O}_{\text {(mixed) }}$ & $-1.18 \times 10^{16}$ & $6.90 \times 10^{15}$ & 0.109 & -0.48 & No & No & \\
\hline
\end{tabular}

* Units for TCO are molecules per square centimetre (molecules $\mathrm{cm}^{-2}$ ). n/a: not applicable.

over land and water do differ in levels of the profile above the LT despite similar retrieval sensitivity at these levels; the differences are just not as systematic as in the LT. However, in addition to the surface and $900 \mathrm{hPa}$ levels in JJA, there are two other instances where trends in $\mathrm{L} 3 \mathrm{~L}$ and $\mathrm{L} 3 \mathrm{~W}$ are significantly different: $600 \mathrm{hPa}$ in JJA and $300 \mathrm{hPa}$ in DJF (in both cases there is no statistically significant trend identified in L3L, whereas the trend in $\mathrm{L} 3 \mathrm{~W}$ is significant). The cause of these discrepancies is not readily apparent given that retrieval sensitivity over land and water is highly comparable in both cases, so further investigation would be needed before we can say with confidence whether or not they have consequences for analyses using the L3O time series, as we have been able to do for the LT.

The main differences in trend discussed above remain if the WLS regression analysis is restricted to only days when L3L and L3W are both present. Results from this restricted analysis are shown in Sect. S8. It is important to note that
MOPITT profile measurements are known to have a drift (Deeter et al., 2017), and this should be corrected for in the data if the focus of the analysis is to use them to quantify temporal changes in $\mathrm{CO}$ over time. Since the intention of the WLS trend analysis presented here is more illustrative, namely to demonstrate trend differences in the data, we have not corrected for this drift. The results should therefore not be taken out of this context (as well as bias correction, verification against a range of other datasets would be required, especially given the large proportion of missing data). We do however provide the reported drift values in Table 3 for context, which shows that the majority of the trends that we have identified appear to be stronger than the measurement drift (at least for the dataset that has greatest retrieval sensitivity at the respective level of the profile). As noted in Sect. 2.1.1, the measurement drift has been significantly reduced in the latest version of the MOPITT products to be released (MOPITT Version 8; Deeter et al., 2019). 

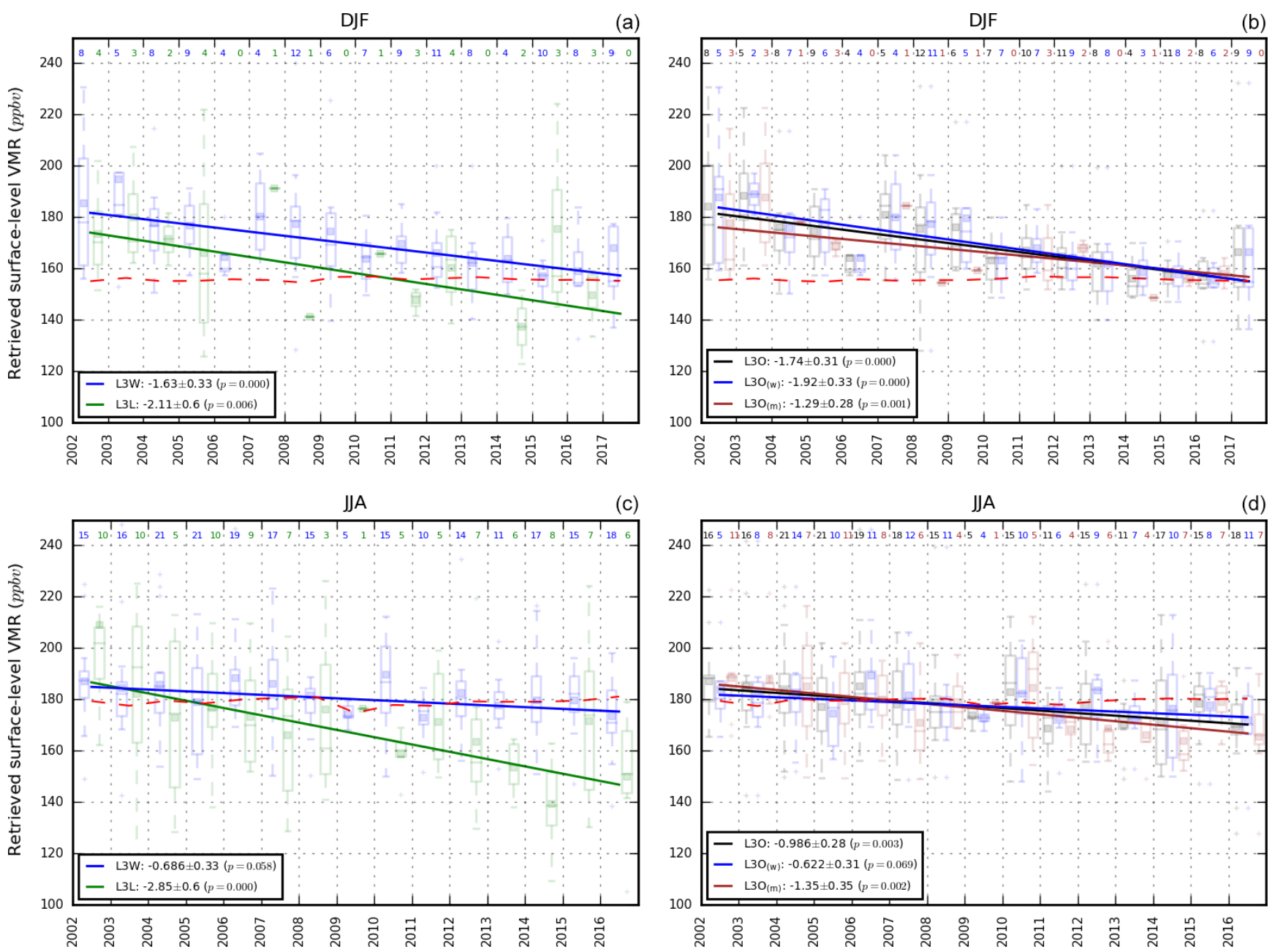

c)

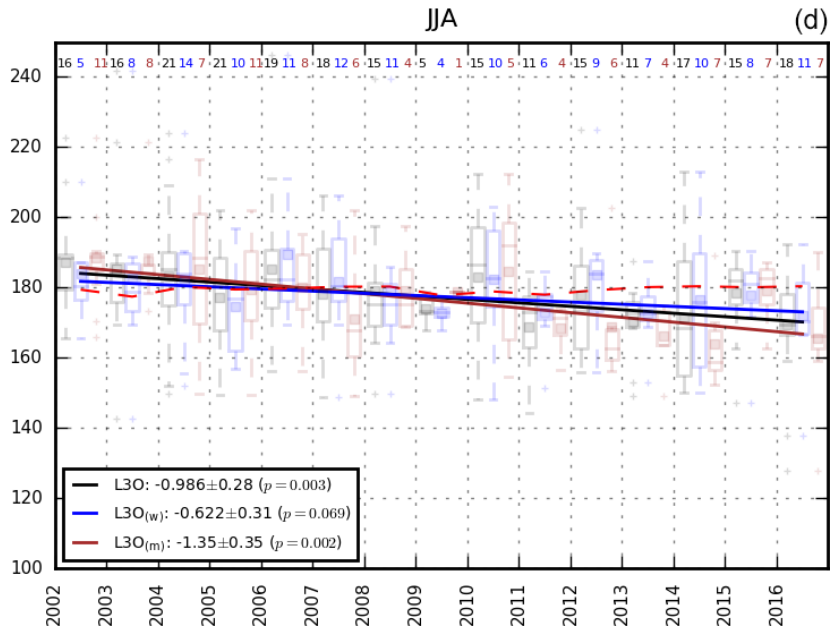

Figure 9. WLS regression best-fit lines calculated from seasonal mean retrieved surface VMR time series in DJF (a, b) and JJA (c, d).

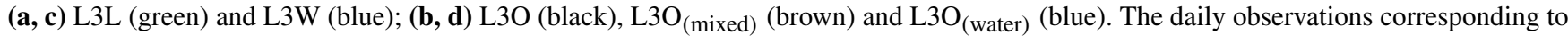
each seasonal mean value are represented by colour-coded boxplots each year, and the seasonal mean value is represented by filled squares. The dashed red line is the mean of the corresponding seasonal mean a priori data from each of the time series in the respective panel. Colourcoded values below the top $x$ axis correspond to the number of observations each season. Values in the legend are the value, standard error and probability of zero value of the trend, respectively.

\subsection{Consideration of MAM and SON}

In this paper we have focused only on DJF and JJA for brevity and clarity. The main findings discussed also hold for MAM and SON, however. In MAM, there is a strong sensitivity contrast in the LT between L3L and L3W, similar to that seen in JJA with retrieval sensitivity much greater over land than water (Fig. 10a). As in JJA, the decreasing trend detected in WLS regression analysis of L3L surface level VMRs in MAM is strongly underestimated in L3W and, consequently, in all L3O subsets (Fig. 10b). In SON on the other hand, AKs indicate a much more comparable degree of LT retrieval sensitivity over both land and water; correspondingly, the detected temporal trends are similar in L3L, L3W and $\mathrm{L} 3 \mathrm{O}$ subsets.

\section{Conclusions}

Users of MOPITT products are advised to filter the data before analysis of profile values in order to maximize the influence of satellite measurements and minimize the impact of a priori CO concentrations on results (MOPITT Algorithm Development Team, 2017; Deeter et al., 2015). In particular, it is advised that retrievals over water, which are known to have lower information content than retrievals over land, are discarded. This is especially so for the analysis of temporal trends in $\mathrm{CO}$ concentrations, owing to the year-to-year stationarity of the a priori. However, for L3 grid boxes that straddle the coastline, the ability to apply such filtering is limited since the products will generally have some contribution from L2 retrievals that take place over both land and 

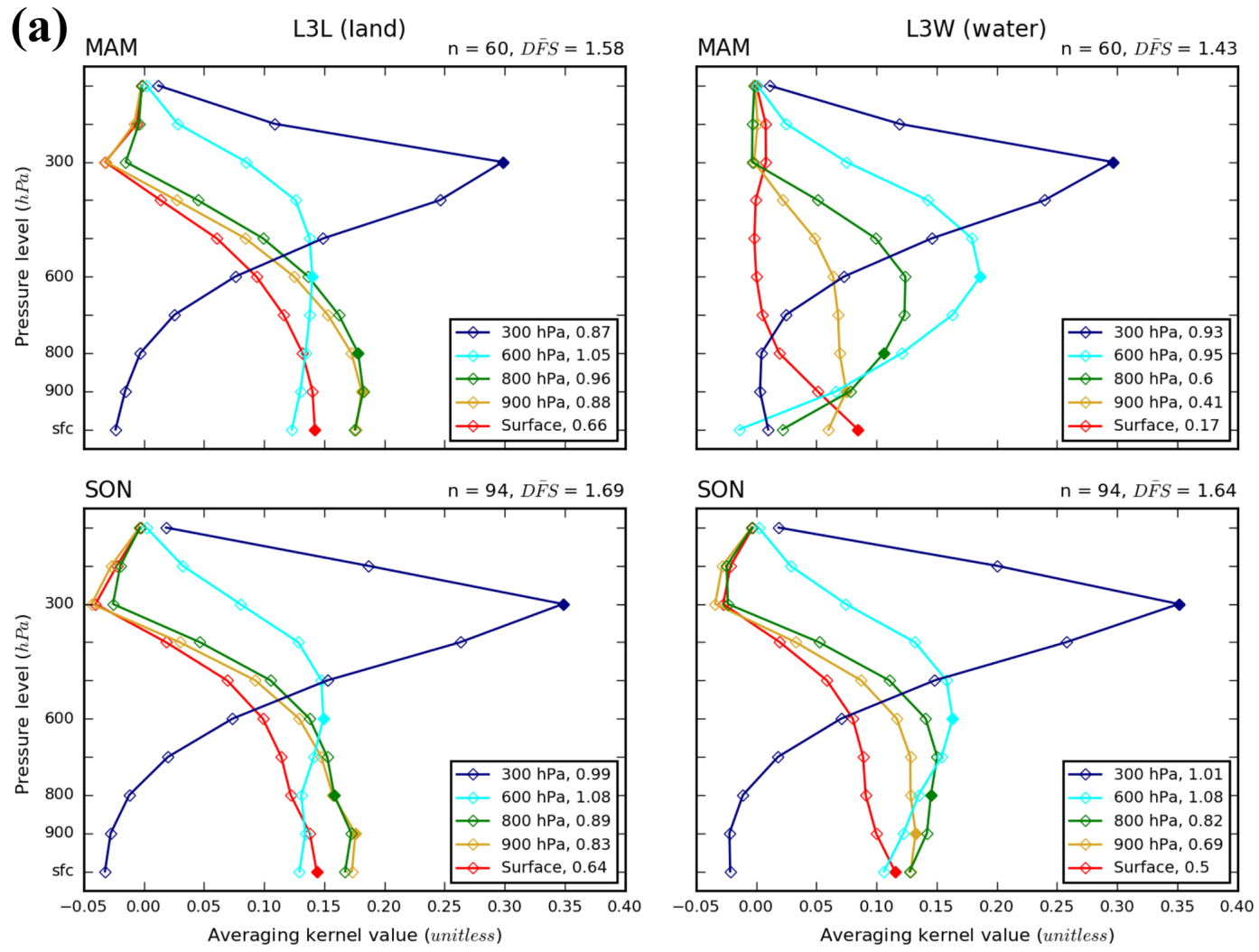

(b) MAM
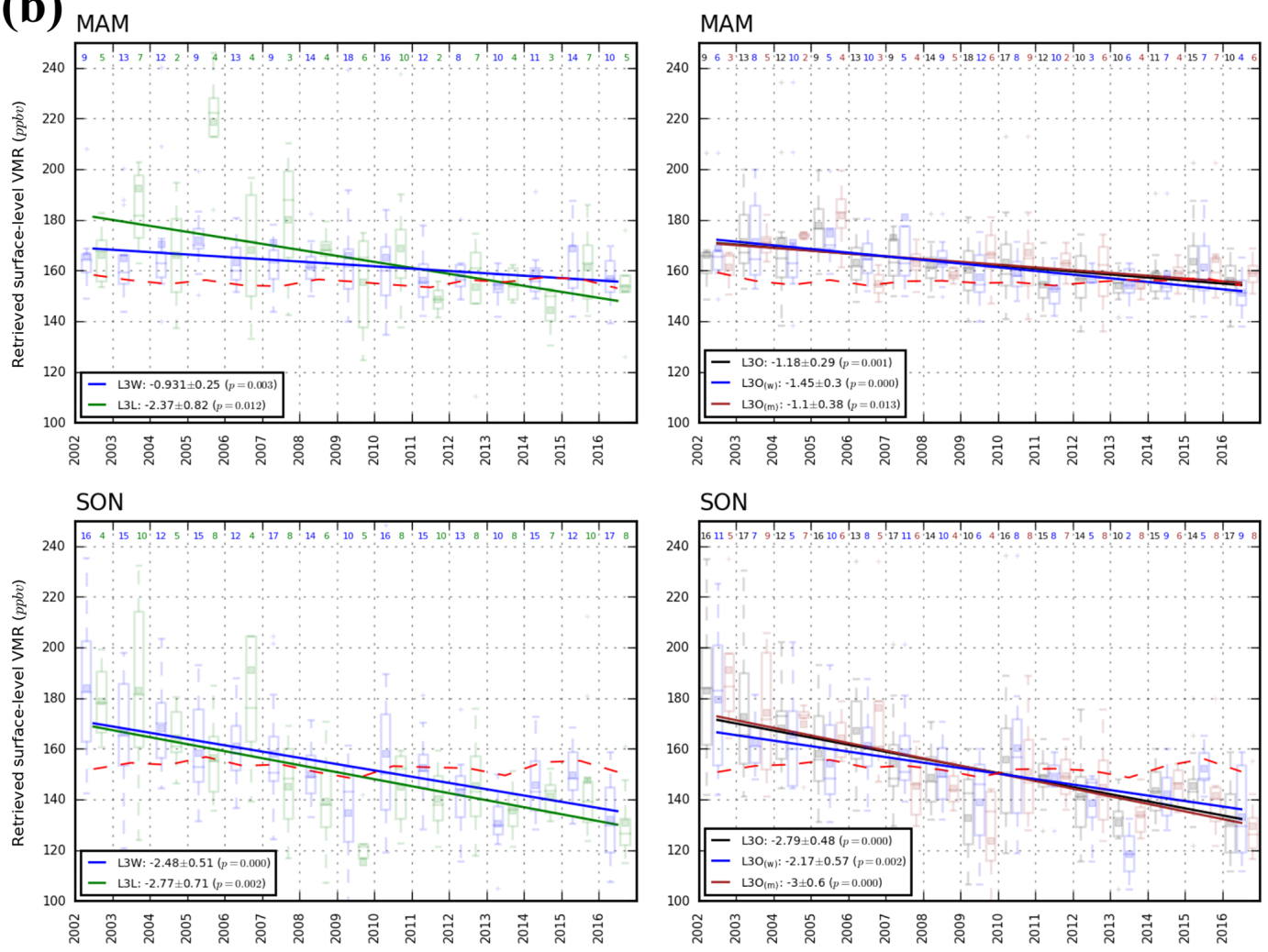

Figure 10. (a) As Fig. 3 but for MAM and SON; (b) as Fig. 9 but for MAM and SON. 
water. This is a direct consequence of the way that L3 products are created.

As we have explicitly demonstrated for the $1^{\circ} \times 1^{\circ} \mathrm{L} 3$ grid box containing the coastal city of Halifax, Canada, the L2 retrieved $\mathrm{CO}$ concentrations, from which the $\mathrm{L} 3$ products are created, differ depending on whether the retrieval took place over land or water. In JJA, and especially near the surface, this is directly linked to differences in the sensitivity of the retrievals to the true $\mathrm{CO}$ profile. The merging of these retrievals to create the $\mathrm{L} 3$ product can significantly affect the statistics of the dataset and the results of temporal trend analysis with the data, with the largest and most statistically significant effects at the surface, where land-water sensitivity contrasts are greatest. As we show, results that are more representative of changes of true $\mathrm{CO}$ concentrations close to the surface within the L3 grid box containing Halifax can only currently be obtained by use of the L2 products, which can be filtered by surface type to maximize information content.

Our results suggest that L2 retrievals over land and water should not both contribute to L3 products in coastal grid boxes. This is consistent with previous data filtering recommendations (MOPITT Algorithm Development Team, 2017; Deeter et al., 2015). The horizontally averaged L3L and L3W time series that we have analysed in this paper are effectively L3 land-only and L3 water-only datasets, and these offer an alternative in this respect that preserves the benefits of available L 3 products - namely, less computing resources and expertise required for their analysis compared to L2 products, which broadens access to the data - but offers users the flexibility to select over which surface the contributing retrievals were performed in order to maximize the information content of L3 data in coastal grid boxes. Although our study has only focused on the city of Halifax, the results suggest that similar studies be performed for other coastal L3 grid boxes before using MOPITT surface CO, since these contain 6 of the top 10 and 43 of the top 100 agglomerations by population and are therefore likely targets for analysis of temporal changes in air pollution indicators such as $\mathrm{CO}$, especially near the surface. The degree of information content loss in the L3 data will depend on the relative contributions of L2 retrievals over land and water to each specific L3 grid box, as well as on the strength of the land-water retrieval sensitivity difference, which in turn depends on scene-specific geophysical variables such as surface temperature and emissivity. Work is currently ongoing to compare the results of analyses conducted with MOPITT L2 and L3 CO data over these cities. 


\section{Appendix A: List of abbreviations}

$\triangle$ RET Percentage differences in retrieved $\mathrm{CO}$ concentrations in $\mathrm{L}_{\mathrm{L}}$ and $\mathrm{L} 3_{\mathrm{W}}$

$\triangle \mathrm{SIM} \quad$ Percentage differences in simulated retrieved $\mathrm{CO}$ concentrations in $\mathrm{L} 3_{\mathrm{L}}$ and $\mathrm{L} 3 \mathrm{~W}$

AK Averaging kernel

CAM-chem Community Atmosphere Model with Chemistry

CAMS Copernicus Atmospheric Monitoring Service

CAMSRA CAMS reanalysis

CO Carbon monoxide

DFS Degrees of freedom for signal

DJF December, January, February

JJA June, July, August

L2 Level 2 data products

L3 Level 3 data products

L3L Area-averaged L2 data for the L3 grid box containing Halifax, for L2 retrievals over land only

L3O Original, as-downloaded L3 time series for the $1^{\circ} \times 1^{\circ} \mathrm{L} 3$ grid box containing Halifax

L3W Area-averaged L2 data for the L3 grid box containing Halifax, for L2 retrievals over water only

LT Lower troposphere (surface-800 hPa levels of the profile in MOPITT data)

MERRA-2 NASA Modern-Era Retrospective Analysis for Research and Applications V2

MOPITT Measurement of Pollution in the Troposphere (instrument)

MT Mid-troposphere (700-500 $\mathrm{hPa}$ levels of the profile in MOPITT data)

NIR Near infrared

SNR Signal-to-noise ratio

TCO Total column CO

TIR Thermal infrared

$T_{\text {sfc }} \quad$ Surface air temperature

$T_{\text {skin }} \quad$ Surface skin temperature

UT Lower troposphere (400-100 hPa profile levels in MOPITT data)

V7 MOPITT Version 7 data products

VMR Volume mixing ratio

$\boldsymbol{X}_{\text {apr }} \quad$ A priori CO VMR profile

$\boldsymbol{X}_{\mathrm{apr}, \mathrm{sim}} \quad$ A priori CO VMR profile used in retrieval simulation

$\boldsymbol{X}_{\text {rtv }} \quad$ Retrieved CO VMR profile

$\boldsymbol{X}_{\text {sim }} \quad$ Simulated retrieved CO VMR profile

$\boldsymbol{X}_{\text {sim, L3L }} \quad$ Simulated retrieved CO VMR profile from L3L

$\boldsymbol{X}_{\text {sim, L3W }}$ Simulated retrieved CO VMR profile from L3W

$\boldsymbol{X}_{\text {true }} \quad$ True CO VMR profile

$\boldsymbol{X}_{\text {tr, sim }} \quad$ True CO VMR profile used in retrieval simulation 
Data availability. The MOPITT V7 joint TIR-NIR L3 and L2 datasets can be accessed at the following URLs, respectively: https://doi.org/10.5067/TERRA/MOPITT/MOP03J_L3.007 (NASA, 2020a) and https://doi.org/10.5067/TERRA/MOPITT/ MOP02J_L2.007 (NASA, 2020b). CAMSRA and ERA-Interim data were downloaded from the ECMWF public datasets portal (https://apps.ecmwf.int/datasets/, last access: 11 June 2020, ECMWF, 2020).

Supplement. The supplement related to this article is available online at: https://doi.org/10.5194/amt-13-3521-2020-supplement.

Author contributions. IA and AW jointly conceived of and designed the study. IA performed data analysis; both authors examined and interpreted the results and prepared the manuscript.

Competing interests. The authors declare that they have no conflict of interest.

Acknowledgements. The authors received funding from the Canadian Space Agency through the Earth System Science Data Analyses program (grant no. 16SUASMPTN), the Canadian National Science and Engineering Research Council through the Discovery Grants Program, and Saint Mary's University. We thank the MOPITT team and ECMWF for providing the data used in this study, and we would also like to thank Dylan Jones (University of Toronto) and James Drummond (Dalhousie University) for their helpful discussions, as well as two anonymous reviewers whose helpful comments greatly improved an earlier version of this paper.

Financial support. This research has been supported by the Canadian Space Agency (grant no. 16SUASMPTN).

Review statement. This paper was edited by Frank Hase and reviewed by two anonymous referees.

\section{References}

Dee, D. P., Uppala, S. M., Simmons, A. J., Berrisford, P., Poli, P., Kobayashi, S., Andrae, U., Balmaseda, M. A., Balsamo, G., Bauer, P., Bechtold, P., Beljaars, A. C. M., van de Berg, L., Bidlot, J., Bormann, N., Delsol, C., Dragani, R., Fuentes, M., Geer, A. J., Haimberger, L., Healy, S. B., Hersbach, H., Hólm, E. V., Isaksen, L., Kållberg, P., Köhler, M., Matricardi, M., McNally, a. P., Monge-Sanz, B. M., Morcrette, J.-J., Park, B.-K., Peubey, C., de Rosnay, P., Tavolato, C., Thépaut, J.-N., and Vitart, F.: The ERA-Interim reanalysis: configuration and performance of the data assimilation system, Q. J. Roy. Meteor. Soc., 137, 553-597, https://doi.org/10.1002/qj.828, 2011.

Deeter, M. N., Emmons, L. K., Francis, G. L., Edwards, D. P., Gille, J. C., Warner, J. X., Khattatov, B., Ziskin, D., Lamarque, J.-F.,
Ho, S.-P., Yudin, V., Attié, J.-L., Packman, D., Chen, J., Mao, D., and Drummond, J. R.: Operational carbon monoxide retrieval algorithm and selected results for the MOPITT instrument, J. Geophys. Res., 108, 4399, https://doi.org/10.1029/2002JD003186, 2003.

Deeter, M. N., Edwards, D. P., Gille, J. C., and Drummond, J. R.: Sensitivity of MOPITT observations to carbon monoxide in the lower troposphere, J. Geophys. Res., 112, D24306, https://doi.org/10.1029/2007JD008929, 2007.

Deeter, M. N., Edwards, D. P., Gille, J. C., Emmons, L. K., Francis, G., Ho, S.-P., Mao, D., Masters, D., Worden, H., Drummond, J. R., and Novelli, P. C.: The MOPITT version $4 \mathrm{CO}$ product: Algorithm enhancements, validation, and long-term stability, J. Geophys. Res., 115, D07306, https://doi.org/10.1029/2009JD013005, 2010.

Deeter, M. N., Martínez-Alonso, S., Edwards, D. P., Emmons, L. K., Gille, J. C., Worden, H. M., Pittman, J. V., Daube, B. C., and Wofsy, S. C.: Validation of MOPITT Version 5 thermalinfrared, near-infrared, and multispectral carbon monoxide profile retrievals for 2000-2011, J. Geophys. Res.-Atmos., 118 , 6710-6725, https://doi.org/10.1002/jgrd.50272, 2013.

Deeter, M. N., Martínez-Alonso, S., Edwards, D. P., Emmons, L. K., Gille, J. C., Worden, H. M., Sweeney, C., Pittman, J. V., Daube, B. C., and Wofsy, S. C.: The MOPITT Version 6 product: algorithm enhancements and validation, Atmos. Meas. Tech., 7, 3623-3632, https://doi.org/10.5194/amt-7-3623-2014, 2014.

Deeter, M. N., Edwards, D. P., Gille, J. C., and Worden, H. M.: Information content of MOPITT CO profile retrievals: Temporal and geographical variability, J. Geophys. Res.-Atmos., 120, 12723-12738, https://doi.org/10.1002/2015JD024024, 2015.

Deeter, M. N., Edwards, D. P., Francis, G. L., Gille, J. C., Martínez-Alonso, S., Worden, H. M., and Sweeney, C.: A climate-scale satellite record for carbon monoxide: the MOPITT Version 7 product, Atmos. Meas. Tech., 10, 2533-2555, https://doi.org/10.5194/amt-10-2533-2017, 2017.

Deeter, M. N., Edwards, D. P., Francis, G. L., Gille, J. C., Mao, D., Martínez-Alonso, S., Worden, H. M., Ziskin, D., and Andreae, M. O.: Radiance-based retrieval bias mitigation for the MOPITT instrument: the version 8 product, Atmos. Meas. Tech., 12, 45614580, https://doi.org/10.5194/amt-12-4561-2019, 2019.

Drummond, J. R., Zou, J., Nichitiu, F., Kar, J., Deschambaut, R., and Hackett, J.: A review of 9-year performance and operation of the MOPITT instrument, Adv. Space Res., 45, 760-774, https://doi.org/10.1016/j.asr.2009.11.019, 2010.

Drummond, J. R., Hackett, J., and Caldwell, D.: Measurements of pollution in the troposphere (MOPITT), in: Optical Payloads for Space Missions, edited by: Shen-En Qian, Wiley and Sons, West Sussex, UK, 639-652, 2016.

Duncan, B. N., Logan, J. A., Bey, I., Megretskaia, I. A., Yantosca, R. M., Novelli, P. C., Jones, N. B., and Rinsland, C. P.: Global budget of CO, 1988-1997: Source estimates and validation with a global model, J. Geophys. Res., 112, D22301, https://doi.org/10.1029/2007JD008459, 2007.

ECMWF: Public Datasets, available at: https://apps.ecmwf.int/ datasets/, last access: 11 June 2020.

Edwards, D. P., Halvorson, C. M., and Gille, J. C.: Radiative transfer modeling for the EOS Terra satellite Measurement of Pollution in the Troposphere (MOPITT) instrument, J. Geophys. Res., 104, 16755-16775, https://doi.org/10.1029/1999JD900167, 1999. 
Francis, G. L., Deeter, M. N., Martínez-Alonso, S., Gille, J. C., Edwards, D. P., Mao, D., Worden, H. M., and Ziskin, D.: Measurement of Pollution in the Troposphere Algorithm Theoretical Basis Document: Retrieval of Carbon Monoxide Profiles and Column Amounts from MOPITT Observed Radiances (Level 1 to Level 2), Atmospheric Chemistry Observations and Modelling Laboratory, National Center for Atmospheric Research, Boulder, Colorado, available at: https://www2.acom.ucar. edu/sites/default/files/mopitt/ATBD_5_June_2017.pdf (last access: 11 June 2020), 2017.

He, H., Stehr, J. W., Hains, J. C., Krask, D. J., Doddridge, B. G., Vinnikov, K. Y., Canty, T. P., Hosley, K. M., Salawitch, R. J., Worden, H. M., and Dickerson, R. R.: Trends in emissions and concentrations of air pollutants in the lower troposphere in the Baltimore/Washington airshed from 1997 to 2011, Atmos. Chem. Phys., 13, 7859-7874, https://doi.org/10.5194/acp13-7859-2013, 2013.

Inness, A., Ades, M., Agustí-Panareda, A., Barré, J., Benedictow, A., Blechschmidt, A.-M., Dominguez, J. J., Engelen, R., Eskes, H., Flemming, J., Huijnen, V., Jones, L., Kipling, Z., Massart, S., Parrington, M., Peuch, V.-H., Razinger, M., Remy, S., Schulz, M., and Suttie, M.: The CAMS reanalysis of atmospheric composition, Atmos. Chem. Phys., 19, 3515-3556, https://doi.org/10.5194/acp-19-3515-2019, 2019.

Lamarque, J.-F., Emmons, L. K., Hess, P. G., Kinnison, D. E., Tilmes, S., Vitt, F., Heald, C. L., Holland, E. A., Lauritzen, P. H., Neu, J., Orlando, J. J., Rasch, P. J., and Tyndall, G. K.: CAM-chem: description and evaluation of interactive atmospheric chemistry in the Community Earth System Model, Geosci. Model Dev., 5, 369-411, https://doi.org/10.5194/gmd-5369-2012, 2012.

MOPITT Algorithm Development Team: MOPITT (Measurements of Pollution in the Troposphere) Version 7 Product User's Guide, Atmospheric Chemistry Observations and Modeling Laboratory, National Center for Atmospheric Research, Boulder, available at: https://www2.acom.ucar.edu/sites/default/files/ mopitt/v7_users_guide_201707.pdf (last access: 11 June 2020), 2017.

NASA: MOPITT CO gridded daily means (Near and Thermal Infrared Radiances) V007, Entry ID: MOP03J_7, ESDS, https://doi.org/10.5067/TERRA/MOPITT/MOP03J_L3.007, 2020a.
NASA: MOPITT Derived CO (Near and Thermal Infrared Radiances) V007, Entry ID: MOP02J_7, ESDS, https://doi.org/10.5067/TERRA/MOPITT/MOP02J_L2.007, $2020 b$.

Pan, L., Edwards, D. P., Gille, J. C., Smith, M. W., and Drummond, J. R.: Satellite remote sensing of tropospheric $\mathrm{CO}$ and $\mathrm{CH}_{4}$ : forward model studies of the MOPITT instrument, Appl. Optics, 34, 6976-6988, https://doi.org/10.1364/ao.34.006976, 1995.

Pan, L., Gille, J. C., Edwards, D. P., Bailey, P. L., and Rodgers, C. D.: Retrieval of tropospheric carbon monoxide for the MOPITT experiment, J. Geophys. Res., 103, 32277-32290, https://doi.org/10.1029/98JD01828, 1998.

Rodgers, C. D.: Inverse Methods for Atmospheric Sounding, Theory and Practice, World Scientific, Singapore, 2000.

Strode, S. A., Worden, H. M., Damon, M., Douglass, A. R., Duncan, B. N., Emmons, L. K., Lamarque, J.-F., Manyin, M., Oman, L. D., Rodriguez, J. M., Strahan, S. E., and Tilmes, S.: Interpreting space-based trends in carbon monoxide with multiple models, Atmos. Chem. Phys., 16, 7285-7294, https://doi.org/10.5194/acp-16-7285-2016, 2016.

Wiacek, A., Li, L., Tobin, K., and Mitchell, M.: Characterization of trace gas emissions at an intermediate port, Atmos. Chem. Phys., 18, 13787-13812, https://doi.org/10.5194/acp-18-137872018, 2018.

Worden, H. M., Deeter, M. N., Edwards, D. P., Gille, J. C., Drummond, J. R., and Nédélec, P.: Observations of near-surface carbon monoxide from space using MOPITT multispectral retrievals, J. Geophys. Res., 115, D18314, https://doi.org/10.1029/2010JD014242, 2010.

Worden, H. M., Deeter, M. N., Frankenberg, C., George, M., Nichitiu, F., Worden, J., Aben, I., Bowman, K. W., Clerbaux, C., Coheur, P. F., de Laat, A. T. J., Detweiler, R., Drummond, J. R., Edwards, D. P., Gille, J. C., Hurtmans, D., Luo, M., Martínez-Alonso, S., Massie, S., Pfister, G., and Warner, J. X.: Decadal record of satellite carbon monoxide observations, Atmos. Chem. Phys., 13, 837-850, https://doi.org/10.5194/acp-13837-2013, 2013.

Worden, H. M., Deeter, M. N., Edwards, D. P., Gille, J., Drummond, J., Emmons, L. K., Francis, G., and Martínez-Alonso, S.: 13 years of MOPITT operations: Lessons from MOPITT retrieval algorithm development, Ann. Geophys.-Italy, 56, 1-5, https://doi.org/10.4401/ag-6330, 2014. 